\title{
Generation of Tyrosine Hydroxylase-Producing Neurons from Precursors of the Embryonic and Adult Forebrain
}

\author{
Marcel M. Daadi ${ }^{1}$ and Samuel Weiss ${ }^{2}$ \\ ${ }^{1}$ NeuroSpheres Limited and ${ }^{2}$ Department of Cell Biology and Anatomy, University of Calgary, Calgary, Alberta, \\ Canada T2N 4N1
}

\begin{abstract}
We have explored the plastic ability of neuronal precursors to acquire different identities by manipulating their surrounding environment. Specifically, we sought to identify potential signals involved in the specification of forebrain dopaminergic neurons. Here we describe culture conditions under which tyrosine hydroxylase (TH) expression is induced in neuronal precursors, which were derived directly from the embryonic striatum and adult subependyma (SE) of the lateral ventricle or generated from multipotent forebrain stem cells. TH was successfully induced in all of these cell types by $24 \mathrm{hr}$ exposure to basic fibroblast growth factor (FGF2) and glial cell conditioned media (CM). The greatest magnitude of the inductive action was on embryonic striatal precursors. Although FGF2 alone induced limited TH expression in striatal cells ( $1.1 \pm 0.2 \%$ of neurons), these actions were potentiated 17.5-fold (19.6 $\pm 1.5 \%$ of neurons) when FGF2 was coadministered with B49 glial cell line CM. Of these $\mathrm{TH}$-immunoreactive cells, $\sim 15 \%$ incorporated bromodeoxyuridine (BrdU), indicating that they were newly
\end{abstract}

Tyrosine hydroxylase (TH) is the first and rate-limiting enzyme in dopamine synthesis. It converts tyrosine to L-dopa. Considerable interest has been generated in regulating the expression of the TH gene, in regions of the CNS that have been depleted of dopamine, as a means of restoring catecholaminergic functions (Mallet, 1996). For example, in models of Parkinson's disease, in addition to transplanting fetal mesencephalic dopamine cells (for review, see Herman and Abrous, 1994; Olanow et al., 1996), strategies to replace the lost dopaminergic innervation have successf ully used cells that have been genetically modified to express TH (Wolff et al., 1989; Horrelou et al., 1990; Fisher et al., 1991; Jiao et al., 1993; for review, see Raymon et al., 1997; Gage, 1998) and directly transferred TH-producing gene cassettes to endogenous striatal cells (During et al., 1994; Horellou et al., 1994; Kaplitt et al., 1994). An alternative approach worthy of consideration is the epigenetic generation of TH-expressing neurons derived from neural multipotential precursor cells (for review, see

\footnotetext{
Received Nov. 9, 1998; revised March 15, 1999; accepted March 22, 1999.

This work was supported by Novartis Canada Limited and the Medical Research Council of Canada. We thank Dr. D. Schubert for providing the B49 glial cell line, M. Y. A. Panlilio for Northern blot technical assistance, and S. E. Daadi for proofreading this manuscript. We also thank the following individuals for their generous supply of the reagents used in this study: CNTF, Drs. R. Dunn and P. Richardson; Sonic hedgehog, Ontogeny Inc.; PDGF, TGF $\beta_{2}, \mathrm{TGF} \beta_{3}$, activin A, BMP-2, FGF2, and FGF1, Chiron Corporation.

Correspondence should be addressed to Dr. Marcel M. Daadi, Center for Neuronal Survival, Montreal Neurological Institute, McGill University, 3801 Rue University, Montreal, Canada H3A 2B4.

Copyright (C) 1999 Society for Neuroscience $\quad 0270-6474 / 99 / 194484-14 \$ 05.00 / 0$
}

generated, and 95\% coexpressed the neurotransmitter GABA. To investigate whether precursors of the adult forebrain subependyma were competent to respond to the instructive actions of FGF2 + CM, they were first labeled in vivo with a pulse of BrdU. Although none of the cells expressed $\mathrm{TH}$ in control, $0.2 \%$ of total cells showed $\mathrm{TH}$ immunoreactivity in FGF2+CMtreated cultures. Under these same conditions only, in vitrogenerated precursors from epidermal growth factor-responsive stem cells exhibited TH expression in 10\% of their total neuronal progeny. Regulation of neurotransmitter phenotype in forebrain neuronal precursors, by the synergistic action of FGF2 and glial-derived diffusible factors, may represent a first step in understanding how these cells are generated in the embryonic and adult brain and opens the prospect for their manipulation in vitro and in vivo for therapeutic use.

Key words: FGFs; glial-derived diffusible factors; tyrosine hydroxylase expression; forebrain precursor cells; subependymal cells; catecholaminergic fate; Parkinson's disease
Anderson, 1992; Baetge, 1993; Brüstle and McKay, 1996; Weiss et al., 1996; Whittemore and Snyder, 1996; Fisher, 1997).

Extrinsic cues control the proliferation of neural precursors and progressively restrict their potential to generate various differentiated progenies (Anderson, 1989). This general concept of neurogenesis emerged from studies of the peripheral nervous system; however, today it is widely accepted as being applicable to the CNS (Edlund and Jessell, 1999). Fibroblast growth factor 2 (FGF2) is a potent mitogen for neuronal precursors of the CNS (Gensburger et al., 1987, Cattaneo and McKay, 1990; Murphy et al., 1990; Ray and Gage, 1994; Daadi et al., 1998). Several in vitro studies have demonstrated that under certain culture conditions, either FGF2 or epidermal growth factor (EGF) can induce extended proliferation of neural precursors derived from embryonic or adult brains [Reynolds and Weiss, 1992; Richards et al., 1992; Kilpatrick and Bartlett, 1993; Ray et al., 1993; Gritti et al., 1996 (for review, see Gage et al., 1995)]. The EGF-responsive stem cells self-renew, produce neurons, astrocytes, and oligodendrocytes, and may participate in repopulating the adult brain (for review, see Weiss et al., 1996; Weiss and van der Kooy, 1998). The principle phenotypes of the neurons generated by these precursors are GABA and substance-P (Ahmed et al., 1995). In preliminary experiments, we found that the coculture of these EGF-generated neuronal precursors with post-natal astrocytes yielded additional neurotransmitter phenotypes, such as neuropeptide Y, somatostatin, methionine-enkephalin, and glutamate (Daadi et al., 1993). Further addition of FGF2 to these 
precursor/astrocyte cocultures generated $\mathrm{TH}$ immunoreactive (TH-IR) neurons (M. Daadi, unpublished results).

Compelling evidence from cell culture studies demonstrates relationships between FGFs and TH-expressing CNS neurons. First, FGF2 regulates the development and differentiation of mesencephalic dopaminergic neurons (Ferrari et al., 1989; Knusel et al., 1990; Mayer et al., 1993; Bouvier and Mytilineou, 1995; Studer et al., 1998). This regulation may be partially caused by the indirect activation of astrocytes by FGF2 (Engele and Bohn, 1991; Gaul and Lubbert, 1992). Second, acidic FGF (FGF1) has been demonstrated to cooperate with catecholamines (Du and Iacovitti, 1995) to induce TH expression in striatal neurons from the embryonic day 13 (E13) mouse. Interestingly, in this study, all of the TH-IR cells were postmitotic (Iacovitti, 1991), and FGF2 was significantly less effective than FGF1 in cooperating with other molecules (Du et al., 1994; Du and Iacovitti, 1995). We have demonstrated previously that the combination of FGF2 and activin or bone morphogenic protein 2 (BMP-2) stimulates $\mathrm{TH}$ gene expression in basal forebrain ventricular zone progenitors (Daadi et al., 1998). However, under these conditions, EGFresponsive stem cell progeny did not differentiate into THexpressing neurons.

The actions of FGF2 and the possible role of astrocytes in secreting factors that induce differentiation (as described above) of neuronal precursors prompted us to examine whether such combinations could induce TH expression in relatively undifferentiated neuronal precursors. We report that FGF2 acts synergistically with glial-derived soluble factor(s) to induce TH expression in neuronal precursors derived directly from the embryonic striatum and adult subependyma (SE) of the lateral ventricles and from the in vitro-propagated multipotent forebrain stem cells.

\section{MATERIALS AND METHODS}

\section{Cell cultures}

Three separate cell cultures were performed.

\section{Primary neuronal culture of the embryonic brain}

Primary neuronal cultures derived from day 14 mouse embryos (E14) were performed as described previously (Daadi et al., 1998). In brief, the dorsal-most aspect of the medial and lateral ganglionic eminences, the cortex, and the mesencephalon were dissected and mechanically dissociated (separately) with a fire-polished Pasteur pipette in serum-free medium composed of a 1:1 mixture of DMEM and F12 nutrient (Life Technologies-BRL). Cells were plated at a density of $10^{6} \mathrm{cells} / \mathrm{ml}$ on poly-L-ornithine-coated ( $15 \mu \mathrm{g} / \mathrm{ml}$; Sigma, St. Louis, MO) glass coverslips in 24-well Nunclon culture dishes with $0.5 \mathrm{ml} /$ well. The culture medium was a serum-free, chemically defined medium composed of DMEM/F12 (1:1) including glucose $(0.6 \%)$, glutamine (2 mM), sodium bicarbonate $(3 \mathrm{~mm})$, and HEPES buffer $(5 \mathrm{~mm})$ [all from Sigma except glutamine (Life Technologies)]. A defined hormone mix and salt mixture (Sigma), including insulin $(25 \mu \mathrm{g} / \mathrm{ml})$, transferrin $(100 \mu \mathrm{g} / \mathrm{ml})$, progesterone $(20 \mathrm{nM})$, putrescine $(60 \mu \mathrm{M})$, and selenium chloride $(30 \mathrm{nM})$ was used in place of serum. Under these culture conditions $\sim 98 \%$ of cells exhibited neuronal morphology [for detailed description of the bioassay, see Daadi et al. (1998)]. Two hours after plating, growth factors and bromodeoxyuridine (BrdU; Sigma) were added to the culture. In cultures maintained for 1 week, half of the cell culture media was replaced after 3 and $5 \mathrm{~d}$ in vitro (DIV). Cells were incubated at $37^{\circ} \mathrm{C}$ in a $95 \%$ air $/ 5 \%$ $\mathrm{CO}_{2}$ humidified atmosphere.

\section{Preparation and differentiation of the EGF-responsive stem cell progeny}

Embryonic day 14 medial and lateral ganglionic eminences were obtained as described above. Dissociated cells were plated at a density of 200,000 cell/ml in Corning T75 (Life Technologies/BRL) culture flasks in the defined media together with $20 \mathrm{ng} / \mathrm{ml}$ EGF. After 7-8 DIV, floating clusters of cells (neurospheres) were centrifuged (400 rpm), and the
EGF-containing media was removed. The pellet was mechanically dissociated and reseeded in fresh EGF-containing media at 50,000 cells/ml for an additional 7-8 DIV until secondary spheres were generated. This entire procedure was performed one additional time. The differentiation of the twice-passaged neurospheres (precursor cell progenies) was performed as follows. Three T75 flasks of 7-8 DIV spheres that had been twice-passaged were spun down for $5 \mathrm{~min}$ at $400 \mathrm{rpm}$. The neurospheres were removed and placed into a $12 \mathrm{ml}$ centrif uge tube and spun down for $5 \mathrm{~min}$ at $600 \mathrm{rpm}$. The EGF-containing supernatant was removed, and the spheres were resuspended in a fresh media (no EGF) plus hormone mix. This step was repeated one more time to ensure the complete removal of EGF from the media. Neurospheres were mechanically dissociated with a fire-narrowed Pasteur pipette and plated under control (media/hormone mix) or TH-inducing conditions (conditioned medium + FGF2) at a density of $10^{6} \mathrm{cells} / \mathrm{ml}$ on poly-L-ornithine-coated $(15$ $\mu \mathrm{g} / \mathrm{ml}$; Sigma) glass coverslips in 24-well Nunclon culture dishes with 0.5 $\mathrm{ml} /$ well. To induce TH expression in intact neurospheres, dissociated EGF-generated neurospheres were plated at a density of 50,000 cells $/ \mathrm{ml}$ in Corning T75 culture flasks in the defined media containing $20 \mathrm{ng} / \mathrm{ml}$ of EGF, $20 \mathrm{ng} / \mathrm{ml}$ of FGF2, and $75 \%$ of conditioned medium (CM). After 7 DIV floating neurospheres were rinsed free of growth factors and CM and plated in control media on poly-L-ornithine-coated glass coverslips for a period of $2 \mathrm{hr}$ before fixation and immunocytochemistry.

\section{Dissociated culture of the adult mouse subependyma}

Previously described methods (Morshead et al., 1994) were used with modifications. The striata from adult male CD1 albino mice were dissected and cut into $1 \mathrm{~mm}$ coronal sections that were transferred into artificial CSF that contained (in mM): $124 \mathrm{NaCl}, 5 \mathrm{KCl}, 1.3 \mathrm{MgCl}_{2}, 2$ $\mathrm{CaCl}_{2}, 26 \mathrm{NaHCO}_{3}$, and $10 \mathrm{D}$-glucose, $\mathrm{pH} \mathrm{7.35,} 280 \mathrm{mOsm}$, and was aerated with $95 \% \mathrm{O}_{2}-5 \% \mathrm{CO}_{2}$ at room temperature. The subependyma surrounding the right and left lateral ventricles was microdissected, chopped into smaller pieces, and transferred to a spinner flask (Bellco) with a magnetic stirrer filled with low-Ca ${ }^{2+}$ artificial CSF that contained (in mM): $124 \mathrm{NaCl}, 5 \mathrm{KCl}, 3.2 \mathrm{MgCl}_{2}, 0.1 \mathrm{CaCl}_{2}, 26 \mathrm{NaHCO}_{3}, 10 \mathrm{~mm}$ D-glucose, pH 7.35, $\sim 280 \mathrm{mOsm}, 1.33 \mathrm{mg} / \mathrm{ml}$ of trypsin $(9000 \mathrm{U} / \mathrm{ml}$ benzoyl-L-arginine ethyl ester), $0.67 \mathrm{mg} / \mathrm{ml}$ of hyaluronidase (2000 $\mathrm{U} / \mathrm{mg}$ ), and $0.2 \mathrm{mg} / \mathrm{ml}$ of kynurenic acid, and was aerated with $95 \%$ $\mathrm{O}_{2}-5 \% \mathrm{CO}_{2}$ at $32-35^{\circ} \mathrm{C}$. After $90 \mathrm{~min}$, tissue pieces were transferred to normal artificial CSF for 5 min before trituration. Tissue was then transferred to DMEM/F12 (1:1, Life Technologies) medium containing $0.7 \mathrm{mg} / \mathrm{ml}$ ovomucoid (Sigma) and was triturated mechanically with a fire-narrowed Pasteur pipette. Cells were spun down at $400 \mathrm{rpm}$ for 5 min, resuspended, and then plated under control (media/hormone mix) or $\mathrm{TH}$-inducing conditions $(\mathrm{CM}+\mathrm{FGF} 2)$ on poly-L-ornithine-coated (15 $\mu \mathrm{g} / \mathrm{ml}$; Sigma) glass coverslips in 24-well Nunclon culture dishes with 0.5 $\mathrm{ml} /$ well.

\section{Growth factors}

The growth factors used were human recombinant brain-derived neurotrophic factor (BDNF) and glial-derived neurotrophic factor (GDNF) (PeproTech Inc., Rocky Hill, NJ); human recombinant platelet-derived growth factor $\beta \beta$ (PDGF), transforming growth factors $\beta_{2}$ and $\beta_{3}$ (TGF $\beta_{2}, \mathrm{TGF} \beta_{3}$,), activin A ( $\beta$-subunit), BMP-2, FGF2, and FGF1 (generously provided by Chiron Corporation, Emeryville, CA); human recombinant transforming growth factor $\alpha$ (TGF $\alpha$; Life Technologies); rat recombinant ciliary neurotrophic factor (CNTF) (generously provided by Drs. R. Dunn and P. Richardson, McGill University); FGF4 and FGF7 (R\&D Systems, Minneapolis, MN); Sonic hedgehog (Shh) (kindly provided by Ontogeny, Cambridge, MA); and calcitonin gene-related peptide (CGRP, Sigma).

\section{Preparation of conditioned media}

$\mathrm{CM}$ was prepared from cultures of postnatal striatal astrocytes and from the B49 rat glial cell line (Schubert et al., 1974) as described by Engele et al. (1991). Astrocyte cultures were prepared from postnatal mice $(0-24 \mathrm{hr})$. Striata were dissected, minced, and transferred into a $15 \mathrm{ml}$ centrifuge tube containing DMEM/F12 (1:1) and 10\% fetal bovine serum (FBS). Tissue was dissociated by trituration with a narrow diameter fire-polished Pasteur pipette and plated in $20 \mathrm{ml}$ of DMEM/F12/ $10 \%$ FBS at a density of 150,000 cells/ml in T75 Corning culture flasks. After they reached confluency, the primary astrocyte monolayers were trypsinized and replated at the same density, then once again allowed to reach confluency. B49 cells (kindly provided by Dr. D. Schubert, Salk Institute, San Diego, CA) were cultured in DMEM/10\% FBS until 
confluency. Confluent astrocyte or B49 glial cell cultures were rinsed once with PBS and twice with serum-free DMEM/F12 (1:1) medium containing hormone mix and replaced in the incubator with $20 \mathrm{ml}$ of the same medium. The CM was collected after 24,48 , or $72 \mathrm{hr}$ and centrifuged at 1000 and $2,000 \times g$ to remove cellular debris. The $\mathrm{CM}$ was carefully removed, filtered, aliquoted, and stored at $-80^{\circ} \mathrm{C}$.

\section{In vitro and in vivo BrdU labeling}

In vitro labeling. To determine whether neurons were newly generated during the first $24 \mathrm{hr}$ culture period, BrdU $(1 \mu \mathrm{M})$ was added $2 \mathrm{hr}$ after plating and remained in the media for the duration of the culture, routinely 1 or $3 \mathrm{DIV}$.

In vivo labeling. In the brains of both embryonic and adult mice, labeling of cells cycling in vivo was performed as follows. Adult male or $13.5 \mathrm{~d}$ post-conception pregnant female CD1 Albino mice were injected intraperitoneally with $100 \mathrm{mg} / \mathrm{kg}$ BrdU dissolved in sterile saline solution. The injection was repeated five times at $2 \mathrm{hr}$ intervals. Thirty minutes after the last BrdU injection, adult animals or dissected E14 embryos were decapitated and dissected for the subependyma zone or the medial and lateral ganglionic eminences, respectively. Tissues were dissociated and cultured as described above. To localize the subependymal precursors in adult forebrain, BrdU-injected mice were killed by transcardiac perfusion with $4 \%$ paraformaldehyde. The brains were cryoprotected in an increasing gradient of sucrose solution, and $10 \mu \mathrm{m}$ cryostat sections were cut and allowed to adhere to glass slides precoated with gelatin/chrome alum for at least $1 \mathrm{hr}$ before immunostaining with anti-BrdU.

\section{Immunocytochemistry}

Rabbit polyclonal antisera and mouse monoclonal antibodies directed against neurotransmitter phenotypes and neural antigens were used as primary antibodies for indirect immunofluorescence. Polyclonal antityrosine hydroxylase (1:1000) and dopamine- $\beta$-hydroxylase (1:200) were purchased from Eugene Tech, Inc. Identical results were obtained with another polyclonal and monoclonal anti-tyrosine hydroxylase obtained from Pel-Freez Biologicals (Rogers, AR) and Incstar, respectively. Monoclonal anti- $\beta$-tubulin (type III, $1: 1000$ ) and polyclonal anti-GABA (1:5000) were purchased from Sigma. Monoclonal antibody against GFAP (1:100) was purchased from Boehringer Mannheim (Mannheim, Germany). Anti-BrdU (1:5) used in proliferation assays was obtained from Amersham (Arlington Heights, IL). Secondary antibodies raised in goat against mouse and rabbit immunoglobulins, conjugated to the fluorophore rhodamine isothiocyanate $(1: 200)$ or fluorescein isothiocyanate (1:100), were purchased from Jackson ImmunoResearch (West Grove, PA). Indirect immunocytochemistry was performed on cells that had been cultured for $24 \mathrm{hr}$ or longer on glass coverslips. Coverslips were fixed with $4 \%$ paraformaldehyde (with $0.1 \%$ glutaraldehyde for antiGABA) for 20 min followed by three washes (10 min each) in PBS. After the PBS rinse, coverslips were processed for dual labeling and incubated with the primary antibodies generated from different species, which were added together in PBS/10\% normal goat serum/0.3 Triton X-100 for $2 \mathrm{hr}$ at $37^{\circ} \mathrm{C}$. After three rinses in PBS, secondary antibodies were applied in PBS for $30 \mathrm{~min}$ at room temperature. Coverslips were then washed three times (10 min each) in PBS, rinsed with water, placed on glass slides, and coverslipped using Fluorsave (Calbiochem, La Jolla, CA) as the mounting medium. Fluorescence was detected and photographed with a Nikon Optiphot photomicroscope. For each experimental condition, the number of TH-IR, BrdU-IR, $\beta$-tubulin-IR, or GABA-IR cells and the total number of live cell nuclei stained with 4',6-diamidine-2'-phenylindole dihydrochloride (DAPI) were determined by examining the entire surface area of each coverslip at $400 \times$ magnification or counting the number of cells in 15 randomly chosen microscopic observation fields per coverslip. The total counts were then expressed as a percentage of the total DAPI-stained nuclei or of the total number of cells expressing the neuronal marker class III $\beta$-tubulin (Lee et al., 1990; Ahmed et al., 1995; Qian et al., 1997). Data represent the mean \pm SEM of experiments performed three or four times on independent culture preparations, each performed in duplicate. Statistical analysis of the data was performed using a one-way ANOVA, and significance of intergroup differences was determined by applying Student's $t$ test. Differences were considered significant at $p<0.05$ and $p<0.01$.

\section{Northern analysis and RT-PCR for neurotransmitter- synthesizing enzyme expression}

Total RNA extraction. After removal of the culture medium, plated cells were lysed in situ using $1 \mathrm{ml}$ of TRIzol (Life Technologies-BRL) per well. Lysates from like samples were pooled and placed on ice for $15 \mathrm{~min}$. Two-tenths volume of chloroform was added, shaken vigorously, and allowed to stand at room temperature for $5 \mathrm{~min}$. The phases were separated in a clinical centrifuge spinning at $2500 \mathrm{rpm}$ for $20 \mathrm{~min}$. The aqueous phase was transferred into a fresh tube, an equal volume of isopropanol was added, the contents were mixed by inversion, and the RNA was allowed to precipitate overnight at $-20^{\circ} \mathrm{C}$. The following day, the tubes were centrifuged at $3500 \mathrm{rpm}$ for $20 \mathrm{~min}$, the supernatant was decanted off, and the pellet was dissolved in $4 \mathrm{M}$ guanidinium isothiocyanate solution (Life Technologies-BRL). The RNA was precipitated using 2 vol of absolute ethanol and incubation at $-20^{\circ} \mathrm{C}$ overnight. When the RNA was required, the tubes were spun at $3500 \mathrm{rpm}$ for $20 \mathrm{~min}$. The pellets were washed in $70 \%$ ethanol, and the tubes were spun again. The air-dried pellets were dissolved in water, and the concentration of each sample was determined spectrophotometrically.

Northern hybridization. Aliquots $(20 \mu \mathrm{g})$ of total RNA were fractionated on agarose formaldehyde gels. The RNA was transferred by capillary action from the gel matrix to Hybond-N+ (Amersham) using $10 \times$ SSC (1.5 M NaCl, $0.15 \mathrm{M}$ sodium citrate, $\mathrm{pH} 7.0)$, and the RNA was fixed onto the membrane by baking. To make a probe to tyrosine hydroxylase, a 48-mer complementary to the mRNA at nucleotides 1435-1482 (GenBank accession M69200) was synthesized and then labeled by $3^{\prime}$-end tailing with $\alpha^{-3}{ }^{33}$ P-dATP (DuPont, Billerica, MA) using terminal transferase (Boehringer Mannheim). The dATP tails, on average, were from three to five nucleotides long per oligonucleotide molecule. The membranes were prehybridized for $30 \mathrm{~min}$ in QuikHyb hybridization mix (Stratagene, La Jolla, CA) at $71^{\circ} \mathrm{C}$. Herring sperm DNA $(1 \mu \mathrm{g}$ per membrane) and labeled probe (10 $\mathrm{ng} / \mathrm{ml}$ hybridization) were added to the prehybridization mix, and the membranes were allowed to incubate for $60 \mathrm{~min}$ at $71^{\circ} \mathrm{C}$. The posthybridization washes consisted of one quick wash in $2 \times$ SSC, $0.1 \%$ SDS at room temperature, two 15 min washes in $2 \times$ SSC, $0.1 \%$ SDS at room temperature, and finally one 30 min wash in $0.1 \times \mathrm{SSC}, 0.1 \% \mathrm{SDS}$ at $60^{\circ} \mathrm{C}$. BioMaxMR autoradiographic film (Kodak) was placed against the air-dried filters and exposed over a $5 \mathrm{~d}$ period at $-80^{\circ} \mathrm{C}$. The sizes of the bands on the developed autoradiographs were verified by calculating the size of RNA corresponding to the apparent migration of the band down the gel relative to standard molecular weight markers.

$R T-P C R$. Aliquots $(1 \mu \mathrm{g})$ of total RNA from the cells were reversetranscribed in the presence of $50 \mathrm{~mm}$ Tris- $\mathrm{HCl}$, pH 8.3, $75 \mathrm{~mm} \mathrm{KCl}, 3 \mathrm{~mm}$ $\mathrm{MgCl}_{2}, 10 \mathrm{~mm}$ DTT, $0.5 \mathrm{~mm}$ dNTPs, and $0.5 \mu \mathrm{g}$ oligo-dT(12-18) (Pharmacia, Dorval, Québec, Canada), with 200 U Superscript RNase H-Reverse Transcriptase (Life Technologies-BRL). PCR primers specific to glutamic acid decarboxylase $\left(\mathrm{GAD}_{67}\right.$; GenBank accession number S61897), to TH (GenBank accession number M69200), and to $\beta$-actin (GenBank accession number M12481) were designed using the Primer Designer software, Version 2.0 (Scientific and Educational Software), and synthesized in the Oligo 1000 DNA Synthesizer (Beckman Instruments). The $\mathrm{GAD}_{67}$ upstream primer corresponded to nucleotides $764-$ 785 , whereas the downstream primer corresponded to nucleotides 10471026 on the complementary strand. The TH upstream primer corresponded to nucleotides $1055-1076$, whereas the downstream primer corresponded to nucleotides 1308-1289 on the complementary strand. The $\beta$-actin sense strand corresponded to nucleotides 512-536 and to nucleotides 950-930 for antisense strand. Aliquots of cDNA equivalent to $40 \mathrm{ng}$ of total RNA were amplified in $25 \mu \mathrm{l}$ reactions containing $10 \mathrm{~mm}$ Tris- $\mathrm{HCl}, \mathrm{pH} 8.3,50 \mathrm{~mm} \mathrm{KCl}, 1.5 \mathrm{~mm} \mathrm{MgCl}_{2}, 50$ pmol of each primer, $400 \mu \mathrm{M}$ dNTPs, and $0.5 \mathrm{U}$ AmpliTaq DNA polymerase (Perkin-Elmer, Emeryville, CA). PCR was performed using the following thermal profile: $4 \mathrm{~min}$ at $94^{\circ} \mathrm{C} ; 1 \mathrm{~min}$ at $94^{\circ} \mathrm{C}, 1 \mathrm{~min}$ at $60^{\circ} \mathrm{C}, 2 \mathrm{~min}$ at $72^{\circ} \mathrm{C}$, for 30 cycles; $7 \mathrm{~min}$ at $72^{\circ} \mathrm{C}$, and finally a soak at $4^{\circ} \mathrm{C}$ overnight. The following day, $15 \mu \mathrm{l}$ aliquots of the amplified products were run on a $2 \%$ agarose Tris-acetate gel containing $0.5 \mu \mathrm{g} / \mathrm{ml}$ ethidium bromide. The products were visualized through a UV transilluminator, captured in a digital format using the DC40 camera, and analyzed with the BioMax 1D Image Analysis software (Kodak digital Science EDAS, Eastman Kodak Company, Rochester, NY) on a Macintosh LC 575 computer. 
Ventral Mesencephalon

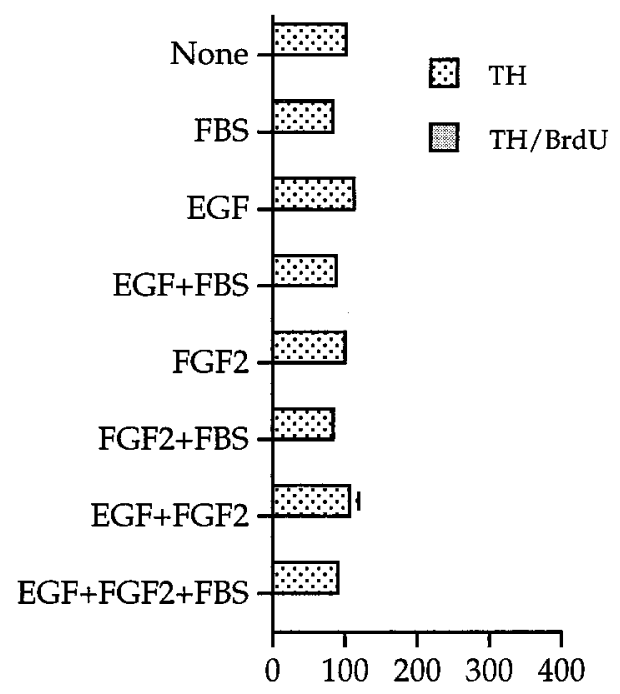

Striatum

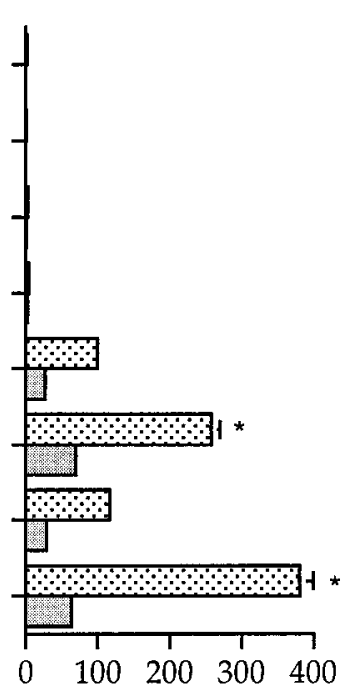

Cortex

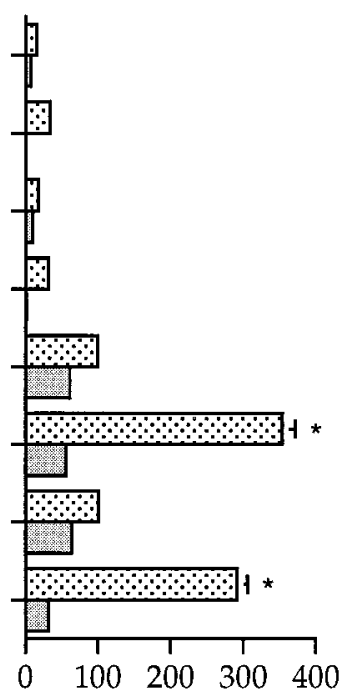

TH-IR neurons (\% FGF2 treated cultures)

Figure 1. Growth factor treatment increases the number of tyrosine hydroxylase-immunoreactive cells in primary cultures derived from different brain regions. Dispersed cells derived from the ventral mesencephalon, striatum, and cortex were grown on poly-L-ornithine-coated glass coverslips in the presence of the indicated factors (FBS, 0.1\%; EGF, $20 \mathrm{ng} / \mathrm{ml}$; FGF2, $20 \mathrm{ng} / \mathrm{ml}$ ). Cells were fixed after 1 DIV and processed for TH and BrdU immunocytochemistry, as described in Materials and Methods. Neurons were identified by their immunoreactivity to anti- $\beta$-tubulin. The TH-IR neurons were expressed as a percentage of the number of TH-IR neurons present in FGF2-treated cultures. In FGF2-treated cultures from the ventral mesencephalon, $1.86 \pm 0.12 \%$ of the total DAPI-stained nuclei and $6.6 \pm 0.4 \%$ of the total neurons were TH-IR, respectively. In FGF2-treated cultures from the striatum, $0.31 \pm 0.06 \%$ of the total cells and $1.1 \pm 0.2$ of the total neurons were TH-IR. Cultures derived from the cortex and treated with FGF2 showed the fewest TH-IR cells: $\sim 0.06 \%$ of the total number of live cells and $0.2 \%$ of the total number of neurons. Results are mean \pm SEM of experiments performed three times on independent culture preparations, each performed in duplicate. Because of the represented scale of the $x$-axes, the error bars do not appear in some of the histograms. The asterisk indicates the level of significance with respect to FGF2-treated cultures; $p<0.05$.

\section{RESULTS}

\section{FGF2 induces the expression of TH in neuronal precursors derived from the E14 striatum and cortex}

We examined the actions of the mitogenic growth factors EGF and FGF2 on the number of cells expressing TH in dissociated cultures derived from the E14 mouse cortex, striatum, and ventral mesencephalon (VM) after $24 \mathrm{hr}$ (1 DIV). Of the three regions examined, as expected under control conditions (no mitogen, no serum), the ventral mesencephalic cultures demonstrated an abundance of TH-IR $\left(\sim 2000 / \mathrm{cm}^{2}, 2 \%\right.$ of the total cells, $7 \%$ of total $\beta$-tubulin-IR neurons) (Fig. 1). Cultures of the cortex or striatum contained few TH-IR cells. Neither serum nor EGF showed any appreciable effects, whereas exposure of striatal or cortical cells to $20 \mathrm{ng} / \mathrm{ml} \mathrm{FGF2}$ resulted in a significant increase in the number of TH-IR cells (Fig. 1). The greatest increase seen in TH-IR cells in the presence of FGF2 was in the striatal cultures that contained $380 \pm 77 \mathrm{TH}-\mathrm{IR}$ cells $/ \mathrm{cm}^{2}$, equivalent to $0.31 \pm$ $0.06 \%$ of the total cells and $1.1 \pm 0.2 \%$ of total $\beta$-tubulin-IR neurons. Under these conditions, however, there was no change in the number of TH-IR cells in cultures derived from the VM. Examination of BrdU incorporation, as an index of newly generated cells (Gratzner, 1982), demonstrated that none of the VMderived TH-IR cells incorporated BrdU; however, 25-30\% of the TH-IR striatal cells were born during the $24 \mathrm{hr}$ culture period (Fig. 1). The addition of $0.1 \%$ FBS potentiated the TH-inducing effects of FGF2 on striatal and cortical cells 2.5-fold, without increasing the proportion of BrdU incorporation (Fig. 1).

These data suggest that FGF2 had two actions on striatal and cortical neuronal precursors. First, FGF2, as has been demonstrated previously, was mitogenic for neuronal precursors that could be induced to express TH. Quantitation of total BrdUlabeled cells confirmed this conclusion. After $24 \mathrm{hr}$, control cultures contained $29 \pm 4 \%$ BrdU-labeled cells, whereas those exposed to FGF2 contained $72 \pm 11 \%$ BrdU-labeled cells. Second, FGF2 (but not EGF, which was equally capable of inducing cell proliferation; $69 \pm 8 \%$ BrdU-labeled cells) could induce the expression of $\mathrm{TH}$ in both newly generated and recently born (see below) striatal and cortical cells, an action that could be potentiated by factors (such as those in serum) that were not inductive alone. Interestingly, this study also revealed that the VM-derived TH-IR cells did not incorporate BrdU. This finding corroborates previous studies (Engele et al., 1991) and demonstrates that the E14 midbrain dopaminergic neurons are all postmitotic. It also supports our hypothesis that for FGF2 to induce TH expression, the precursor cells need to be at the newly generated or recently postmitotic stage.

\section{TH induction by FGF2 is dramatically enhanced by media conditioned by astrocytes, and in particular the B49 glial cell line}

Given the well known actions of astrocytes in enhancing the differentiation and survival of mesencephalic dopaminergic neurons (Denis-Donini et al., 1984; Engele et al., 1991; O’Malley et al., 1992; Takeshima et al., 1994) and forebrain neuronal precursors (Daadi et al., 1993), we examined the putative cooperative actions of media conditioned (CM) by astrocytes or the B49 glial cell line on FGF2 induction of TH in cultured striatal cells. The 


\author{
Str. Astro. (24hr)
}

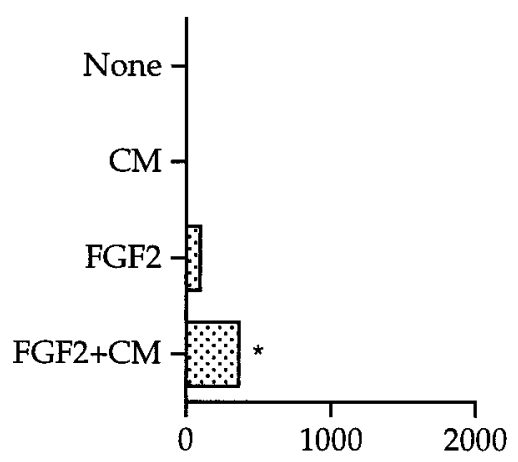

Str. Astro. (72hr)

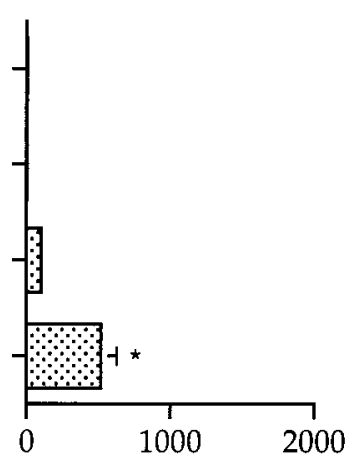

B49 cell line ( $24 \mathrm{hr})$

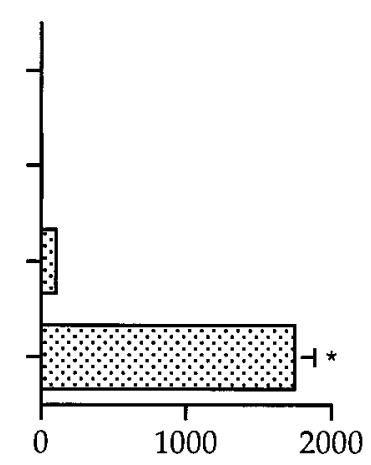

TH-IR neurons (\% FGF2 treated cultures)

Figure 2. Conditioned media from glial cells potentiates the actions of FGF2 on the number of tyrosine hydroxylase-immunoreactive cells in cultures of striatal neuronal precursors. Dissociated striatal cells $\left(5 \times 10^{5}\right)$ were grown on poly-L-ornithine-coated glass coverslips under the indicated conditions $(\mathrm{CM}, 75 \%$; FGF2, $20 \mathrm{ng} / \mathrm{ml})$. Cells were fixed after a $24 \mathrm{hr}$ culture period and processed for indirect immunocytochemistry for TH, as described in Materials and Methods. Because control culture contained between 0 and 8 TH-IR cells and to allow for multiple comparison, the number of TH-IR neurons present in FGF2-treated cultures was taken as 100\% (1.1 $\pm 0.2 \mathrm{TH}-\mathrm{IR}$ of the total number of neurons). Results are the mean \pm SEM of three independent experiments, each performed in duplicate. Because of the represented scale of the $x$-axes, the error bars do not appear in some of the histograms. The asterisk indicates the level of significance with respect to CM-treated cultures; $p<0.01$.

CM was collected into serum-free media, as described in Materials and Methods, over a 24 or $72 \mathrm{hr}$ period. The addition of CM (either one as listed above) had no effect on the number of TH-IR cells in $24 \mathrm{hr}$ striatal cell culture (Fig. 2). When CM from striatal astrocytes collected after 24 or 72 hr was combined with FGF2, the number of TH-IR cells increased from $0.31 \pm 0.06 \%$ of the total cells $(1.1 \pm 0.2 \%$ of total neurons $)$ in cultures treated with FGF2 alone to $1.13 \pm 0.16 \%$ (4.0 $\pm 0.5 \%$ of total neurons) and $1.63 \pm 0.34 \%(5.8 \pm 1.2 \%$ of total neurons), respectively (Fig. 2). $\mathrm{CM}$ derived from mesencephalic glia did not further increase the number of TH-IR cells (data not shown). However, a greater cooperative action was observed when FGF2 was combined with CM derived from a confluent culture of B49 glial cells. Coapplication of FGF2 and CM from B49 cells resulted in a 17.5-fold increase (to $5.50 \pm 0.43 \%$ of total cells; $19.6 \pm 1.5 \%$ of total neurons) in the number of TH-IR striatal cells (Figs. 2, 3A,D).

Despite the difference in collection time observed for $\mathrm{CM}$ from striatal astrocytes, there was no increase in TH-inducing activity (as assessed by the numbers of TH-IR cells) when B49 CM was collected for $72 \mathrm{hr}$ (data not shown). As was the case for the addition of serum, CM did not increase the proportion of $\mathrm{TH}$ expressing cells that had incorporated BrdU. In fact, the proportion of TH-IR cells that were newly generated during the $24 \mathrm{hr}$ culture period decreased from $25-30 \%$ in the presence of FGF2 to $12-15 \%$ with $\mathrm{FGF} 2+\mathrm{CM}$. The significance of these proportions is discussed further below.

The individual actions of FGF2 and CM (henceforth synonymous with B49 CM) were dose dependent (Fig. 4). While using a fixed concentration of FGF2 $(20 \mathrm{ng} / \mathrm{ml})$, increasing proportions of CM gradually potentiated the number of TH-IR cells observed after $24 \mathrm{hr}$. Maximal effects of CM were achieved when used at $50-75 \%$ of the total media (Fig. $4 A$ ). Similarly, at a fixed concentration of $75 \% \mathrm{CM}, \mathrm{FGF} 2$ actions were first detected at 1 $\mathrm{ng} / \mathrm{ml}$, and the maximal effect was achieved with $50-100 \mathrm{ng} / \mathrm{ml}$ (Fig. 4B). Fixed concentrations of FGF1 (examined at 20 and 50 $\mathrm{ng} / \mathrm{ml}$ ) yielded $\sim 50 \%$ of the efficacy of FGF2 (Fig. $4 B$ ).

Because the B49 glial cell line fueled the discovery of GDNF, a potent survival factor for midbrain dopaminergic neurons (Engele et al., 1991; Lin et al., 1993), we asked whether GDNF is the glial-derived factor that cooperates with FGF2 to induce TH expression. The results shown in Figure 5 demonstrate that GDNF is not involved in the rapid induction of $\mathrm{TH}$ expression in striatal neuronal precursors.

\section{Relationship between proliferation, differentiation, and TH induction in striatal neuronal precursors}

The TH-inducing actions of FGF2 + CM, particularly in cells that also incorporated BrdU, suggest that newly generated or recently postmitotic neurons would be most susceptible to manipulation. To directly demonstrate that actively mitotic neuronal precursors are induced to express TH, a 2 hr pulse of BrdU was applied at 8 and $22 \mathrm{hr}$ in culture, and cells were examined at $24 \mathrm{hr}$. These experiments revealed that $4.3 \pm 1.4 \%$ and $3.9 \pm 0.8 \%$ of the total TH-IR cells have progressed through the $\mathrm{S}$ phase of the cell cycle during the period of BrdU availability ( $2 \mathrm{hr}$ ) after 8 and $22 \mathrm{hr}$ in culture, respectively. To further understand the mechanism of the TH induction, we examined the relationship between time dependence and proliferative actions of FGF2+CM on the induction of TH expression. Although FGF2 + CM could induce $5.11 \pm 0.73 \%$ of the total cells to express TH when applied at plating, if delayed by only $24 \mathrm{hr}$ this was reduced to $0.10 \pm 0.02 \%$ cells. If delayed by $4 \mathrm{~d}, \mathrm{FGF} 2+\mathrm{CM}$ was entirely without effect. Examination of endogenous proliferation (i.e., of control cultures) showed a correlative, precipitous decline in the numbers of proliferating cells. Although $25.50 \pm 0.68 \%$ BrdU-labeled cells were detected over the first $24 \mathrm{hr}$, if detection was delayed by $2 \mathrm{~d}$ only $4.34 \pm 0.06 \%$ of the total cells incorporated BrdU in the last $24 \mathrm{hr}$ culture period. This dropped to $0.39 \pm 0.08 \%$ if BrdU was added after 4 DIV, and the cultures were processed for BrdU immunocytochemistry after 5 DIV. Thus, the ability to induce TH declines with the proliferative capacity of the striatal precursors. Although control cultures showed between 25 and $29 \%$ of cells incorporating BrdU, this increased almost threefold in response to FGF2, yet it actually decreased threefold $(8.73 \pm 1.7 \%)$ in the presence 

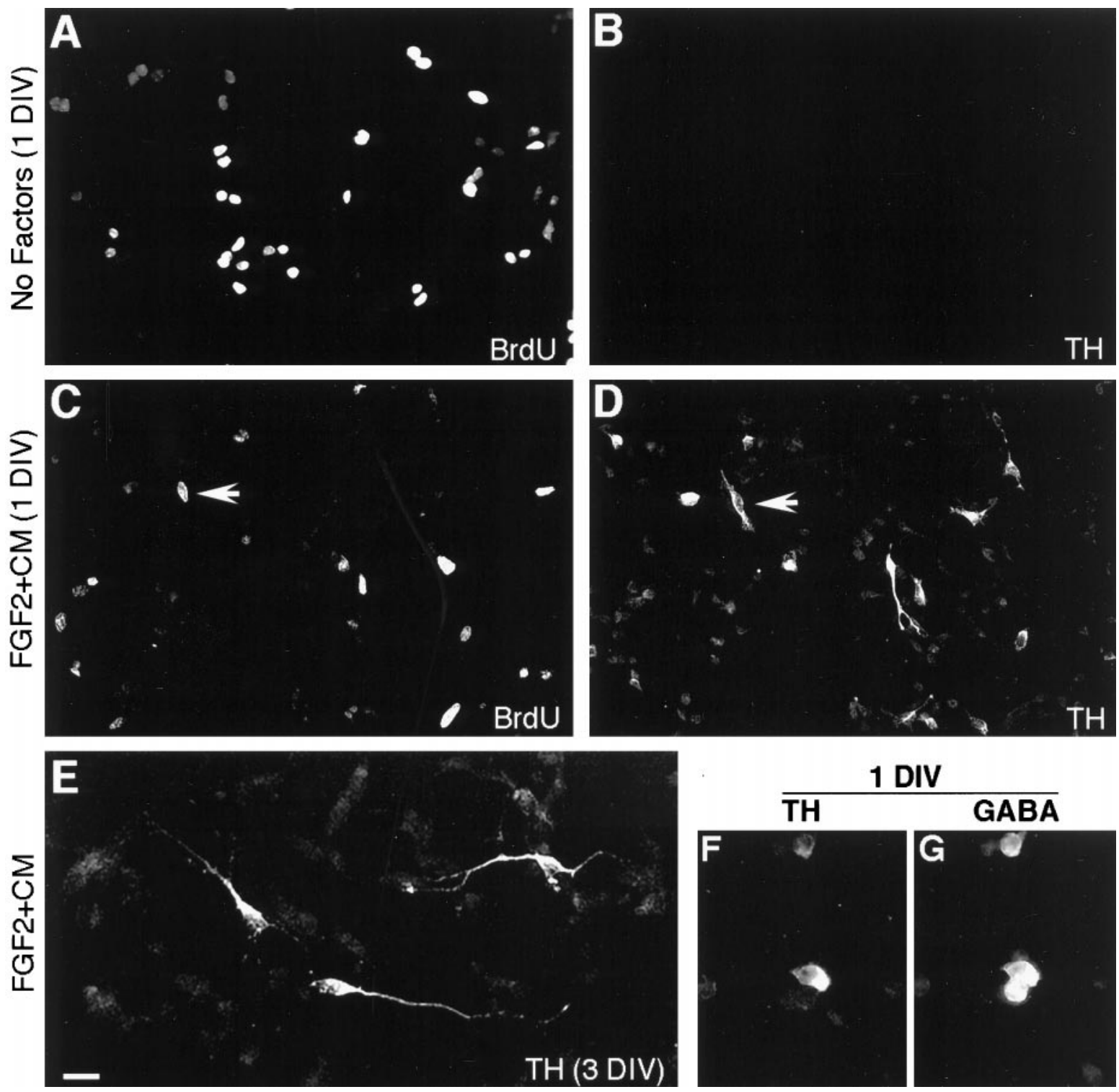

Figure 3. The combination of FGF2 and CM induces TH immunoreactivity in striatal neuronal precursors. Dissociated cells $\left(5 \times 10^{5}\right)$ of the E14 striatum were cultured on poly-L-ornithine-coated glass coverslips in serum-free medium without $(A, B)$ or with $(C-G) 75 \%$ of $\mathrm{B} 49$ glial cell line-conditioned media and FGF2 $(20 \mathrm{ng} / \mathrm{ml})$ for $24 \mathrm{hr}(A-D, F, G)$ and $3 \mathrm{~d}(E)$. Two hours after plating, all culture wells received $1 \mu \mathrm{M}$ BrdU (a marker for DNA synthesis) (Gratzner, 1982). Fixed cells were processed for dual immunocytochemistry (as described in Materials and Methods) for TH and $\operatorname{BrdU}(A-D)$, TH and GABA $(F, G)$, or single TH immunocytochemistry $(E)$. In control cultures $(A, B)$ the newly generated cells that had incorporated BrdU do not express TH. In FGF2+CM-treated cultures $(C, D)$, the arrow shows one example of a cell that had incorporated BrdU and expressed TH. After 3 DIV, TH-IR cells developed typical neuronal morphology $(E)$. $F$, $G$, Example of a 24-hr-old TH-IR cell that also coexpressed the neurotransmitter GABA. Scale bar (shown in $E$ ): $A-D, 40 \mu \mathrm{m}: E, 25 \mu \mathrm{m}: F, G, 10 \mu \mathrm{m}$.

of CM alone. Further addition of FGF2 to CM-containing medium did not further increase the number of BrdU-labeled cells $(9.08 \pm 1.91 \%)$. Thus, it appears that the mechanism that underlies the differentiation actions of $\mathrm{CM}$ in inducing $\mathrm{TH}$ may be associated with attenuating the endogenous proliferative capacity of the striatal precursors.

To ascertain whether the most recently generated neuronal precursors are the most susceptible to express $\mathrm{TH}$, we prelabeled this population in vivo. This was performed by a series of BrdU injections into E13.5 pregnant female mice. Dissociated cultures of the embryonic striata were grown for $24 \mathrm{hr}$ in the absence or presence of $\mathrm{FGF} 2+\mathrm{CM}$, and an examination of $\mathrm{TH}$ and $\mathrm{BrdU}$ coexpression followed. Of the $4.0 \pm 0.13 \%$ cells that expressed $\mathrm{TH}, 44 \%$ were also BrdU-IR. This result confirms that both mitotically active and most recently generated neuronal precursors are particularly sensitive to $\mathrm{TH}$ induction.

\section{FGF2+CM stimulates TH mRNA expression}

The induction of TH expression in response to FGF2+CM could occur either by an activation of the gene encoding the enzyme or by posttranslational actions and enhancement of protein levels. To examine these possibilities, we isolated total RNA from control cultures of striatal cells and those treated with FGF2+CM and then measured the levels of TH mRNA with Northern blot analysis (Fig. 6A). A single band corresponding to the $1.8 \mathrm{~kb} \mathrm{TH}$ transcript (Ichikawa et al., 1991) was detected only in the cultures treated with FGF2+CM. Thus, the induction of TH expression occurs at the level of gene transcription. 

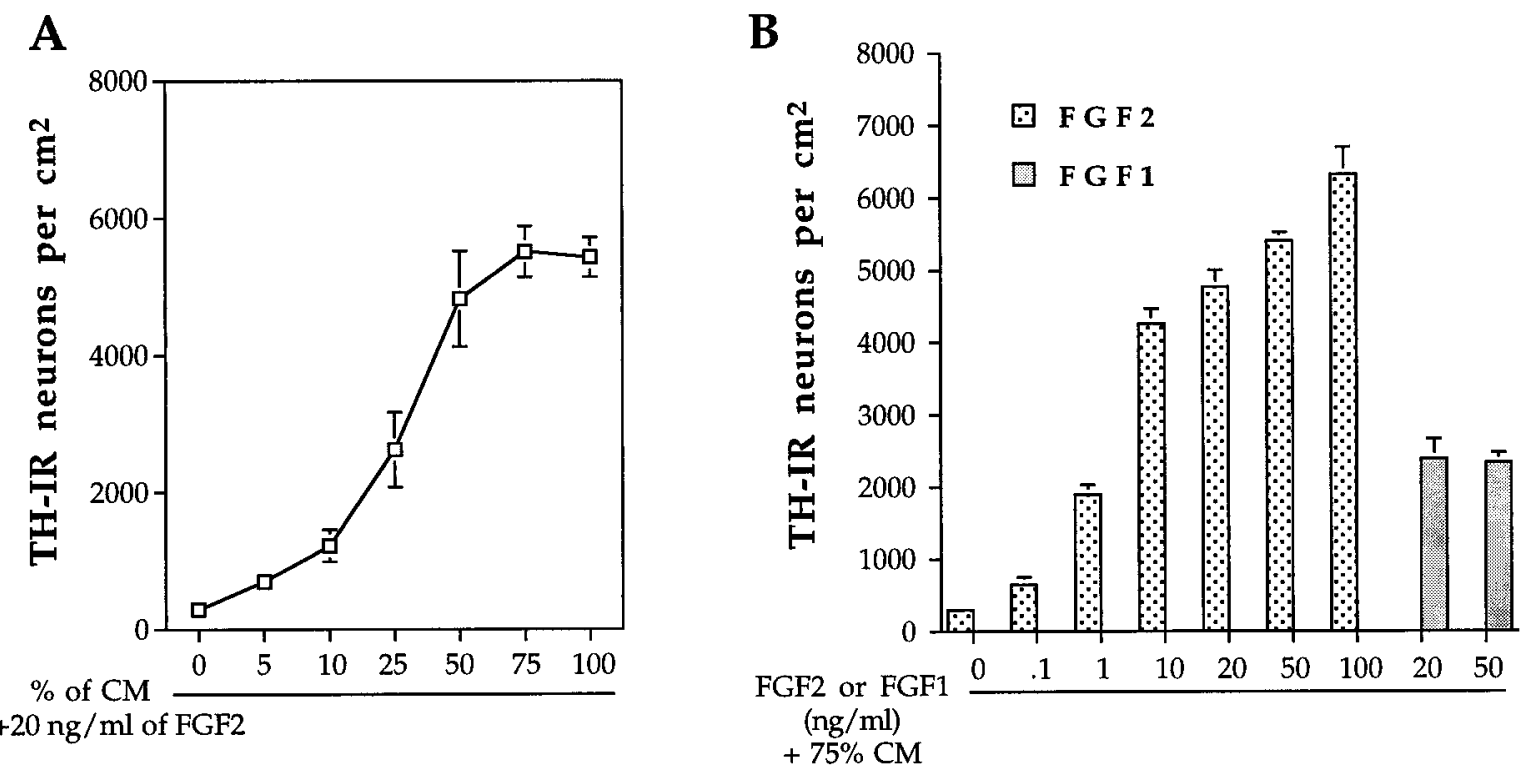

Figure 4. CM and FGF2 cooperate synergistically in a dose-dependent manner to induce TH expression in striatal neuronal precursors. $A$, Striatal cells were cultured in the presence of $20 \mathrm{ng} / \mathrm{ml} \mathrm{FGF} 2$ and increasing concentrations of CM for a period of $24 \mathrm{hr}$ and processed for TH immunocytochemistry, as described in Materials and Methods. A fluorescent-field microscope with $40 \times$ objective was used to count the total number of TH-IR cells in the entire area of each coverslip. B, Dissociated cells were cultured in the presence of 75\% CM and increasing concentrations of either FGF2 or FGF1, and then processed for $\mathrm{TH}$ immunocytochemistry and quantified as described in Materials and Methods. Data represent the mean \pm SEM of experiments performed three times on independent culture preparations, with two replicates for each condition within the independent experiments.

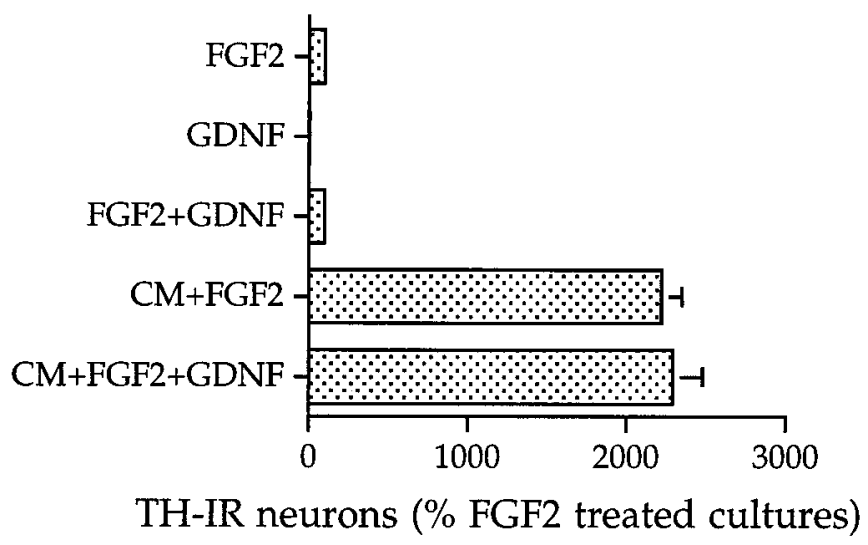

Figure 5. GDNF does not mimic the actions of CM on the appearance of tyrosine hydroxylase-immunoreactive neurons in cultures of striatal cells. Striatal cells were plated at a density of $5 \times 10^{5}$ cells per well on poly-L-ornithine-coated glass coverslips and cultured under the indicated conditions for $24 \mathrm{hr}$ before being processed for $\mathrm{TH}$ immunocytochemistry. Similar to Figures 1 and 2, the number of TH-IR neurons was represented as a percentage of the FGF2-treated cultures in which $1.1 \pm$ 0.2 of the total number of neurons are TH-IR (see Results). Results are mean \pm SEM of four independent experiments, each performed in duplicate.

\section{FGF2+CM regulates both GABA and TH expression in the striatal neuronal precursors}

Given that the majority of the striatal cells express GABA in vitro (Mizuno et al., 1994; Max et al., 1996; Daadi et al., 1998) and in vivo (Mugnaini and Ortel, 1985), we investigated whether GABA expression might also be regulated by FGF2+CM treatment. Application of FGF2+CM for $24 \mathrm{hr}$ simultaneously stimulated the TH and GABA expression at both the protein and mRNA levels (Fig. 6B; Table 1). By contrast, after 3 DIV, control cultures showed an increase in the number of GABA-IR neurons, whereas those exposed to FGF2+CM demonstrated a decrease in the numbers of both TH- and GABA-IR cells (Table 1). This finding was confirmed at the mRNA level using semiquantitative RT-PCR analysis (Fig. 6B). We then asked whether $\mathrm{TH}$ and GABA coexist in the same cells. Double-labeling immunocytochemistry with antibodies to $\mathrm{TH}$ and GABA revealed that $95 \%$ of the total TH-IR cells coexpressed GABA (Fig. $3 F, G$; Table 1). These data confirmed our previous finding (Daadi et al., 1998) and demonstrated at both the cellular and molecular level that a subset of the striatal neuronal precursors express $\mathrm{TH}$ transiently after $24 \mathrm{hr}$ exposure to FGF2+CM. The percentage of neuronal precursors that expressed $\mathrm{TH}$ after 3 DIV remained the same after 7 DIV (data not shown), suggesting a stable induction of TH gene expression and a heterogeneity within the striatal precursors (see Discussion).

\section{FGF2+CM induces precursors of the adult forebrain subependyma to express $\mathrm{TH}$ in vitro}

The SE is the adult equivalent of the embryonic subventricular zone (SVZ) (Boulder Committee, 1970), and it contains a population $(0.2-0.4 \%)$ of neural stem cells that under normal conditions are relatively quiescent and generate the constitutively proliferating progeny ( $10 \%$ of the SE cells) that have a cell-cycle time of 12.7 hr (Morshead and van der Kooy, 1992; Morshead et al., 1998). Therefore, in the next series of experiments, we asked whether $\mathrm{FGF} 2+\mathrm{CM}$ could induce $\mathrm{TH}$ in neuronal precursors derived from the adult SE (presumably produced by stem cells within the SE). To accomplish this, we first labeled the SE precursors of the adult mouse forebrain in vivo by six injections of BrdU, given at $2 \mathrm{hr}$ intervals (Morshead et al., 1994). Figure 7B shows the location of the SE precursors (BrdU-IR) surrounding the lateral ventricle of the adult forebrain. Thirty minutes after the last BrdU injection, the SE was dissected, enzymatically dispersed, and cultured in the absence or presence of FGF2 + CM. The cells were fixed and examined for TH and BrdU 


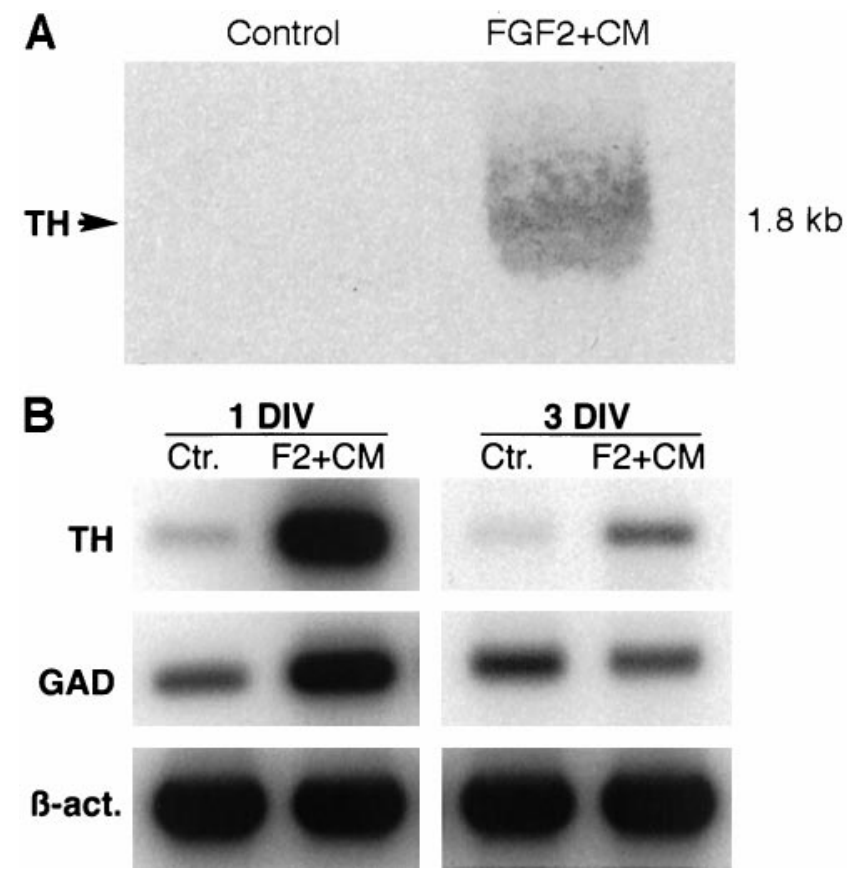

Figure 6. Regulation of TH and GABA expression in the striatal neuronal precursors. $A$, Total RNA was isolated from the harvested 1-d-old cells and assayed ( $20 \mu \mathrm{g}$ of RNA per lane) for the expression levels of TH transcripts $(1.8 \mathrm{~kb}$ ) by Northern blot analysis (see Materials and Methods for description of probe used and the conditions of hybridization). $B$, Total RNA samples were extracted from 1- and 3-d-old cultures that had been treated as indicated. The relative abundance of $\mathrm{TH}, \mathrm{GAD}_{67}$, and $\beta$-actin transcripts was assessed by RT-PCR (see Materials and Methods for details about the primer sequences and the conditions of the RT-PCR).

immunoreactivity 1 and $3 \mathrm{~d}$ after plating. In control conditions, many cells were labeled with BrdU, but none were TH-IR. However, cultures treated with FGF2+CM showed newly generated TH-IR cells. Figure 7 illustrates examples of cells that expressed both $\mathrm{TH}$ and BrdU immunoreactivity after 1 (Fig. $7 C, D)$ and $3 \mathrm{~d}($ Fig. $7 E, F)$ in culture. Younger TH-IR cells $(1 \mathrm{~d}$ old) exhibited features of undifferentiated cells, with small, round cell bodies and no or short processes. After 3 DIV, the TH-IR cells gained features typical of differentiated neurons, with small bipolar or multipolar cell bodies, diameters varying between 8 and $14 \mu \mathrm{m}$, and long, thin, and aspiny neuritic processes (Fig. $7 F$ ). Quantitative data from three independent experiments indicated that of the total number of cells plated, $0.23 \pm 0.03 \%$ exhibited TH-IR. Of those cells exhibiting TH immunoreactivity, $63 \%$ were BrdU-IR, which suggests that they were derived from the proliferating cells of the adult SE and were born during the $12 \mathrm{hr}$ that preceded the primary culture. In contrast to the embryonic striatal precursors, the number of SE-derived TH-IR cells did not decrease over time (data not shown).

\section{Generation of TH-expressing neurons from embryonic forebrain multipotent stem cells}

In the final series of experiments, we asked whether neuronal precursors derived from EGF-responsive stem cells could be induced to express TH. Clones (or neurospheres) of undifferentiated cells derived from the EGF-responsive stem cells (see Materials and Methods) were propagated (passaged) numerous times, dissociated, and plated in serum-free medium containing 1 $\mu \mathrm{M}$ BrdU, in the absence or presence of FGF2+CM. After $24 \mathrm{hr}$
Table 1. Coexpression of GABA and TH in cultures of striatal precursors after treatment with FGF2 and conditioned media

\begin{tabular}{llccc} 
& Culture & \multicolumn{3}{c}{ (\% of $\beta$-tubulin-IR) } \\
\cline { 3 - 5 } Condition & period & GABA & TH & GABA/TH \\
\hline Control & 1 DIV & $1.0 \pm 0.1$ & $0 \pm 0$ & $0 \pm 0$ \\
& 3 DIV & $20 \pm 1.4$ & $0 \pm 0$ & $0 \pm 0$ \\
CM + FGF2 & 1 DIV & $37.2 \pm 6.9^{*}$ & $17.0 \pm 2.9^{*}$ & $14.8 \pm 1.8^{*}$ \\
& 3 DIV & $10.5 \pm 1.3^{*}$ & $4.1 \pm 0.6^{*}$ & $3.1 \pm 0.5^{*}$
\end{tabular}

Striatal precursors were cultured on poly-L-ornithine-coated glass coverslips in defined culture medium with or without FGF2 $(20 \mathrm{ng} / \mathrm{ml})$ and CM $(75 \%)$. Cells were fixed after 1 and 3 DIV and immunostained with monoclonal antibodies directed against TH, GABA, and $\beta$-tubulin antigens (see Materials and Methods for details). Quantitation was performed as described in Materials and Methods, and the number of TH-IR cells was expressed as a percentage of the total number of $\beta$-tubulin-IR neurons. Results are mean \pm SEM of three independent experiments, each performed in duplicate. The asterisk indicates the level of significance with respect to control: $p<0.05$.

the cultures were processed for $\mathrm{TH}$ and BrdU immunocytochemistry. As was the case for isolated cells of the adult SE, TH-IR cells were observed only in cultures treated with FGF2+CM (Fig. $8 A$ ). TH immunoreactivity was not observed in control cultures nor when $20 \mathrm{ng} / \mathrm{ml} \mathrm{FGF2}$ was coincubated with $50 \mathrm{ng} / \mathrm{ml} \mathrm{BDNF}$, CNTF, PDGF, TGF $\alpha, \mathrm{TGF} \beta_{2}, \mathrm{TGF} \beta_{3}, \mathrm{GDNF}$, activin A, BMP-2, GDNF, Shh, or CGRP (data not shown). In agreement with previous studies (Ahmed et al., 1995; Arsenijevic and Weiss, 1998), we have found that most of cells $(>80 \%)$ in these cultures were astrocytes. Thus, only a minor proportion of dissociated cells (1-2\% in both control and treated cultures) expressed the neuronal marker $\beta$-tubulin. Quantitative data from three independent culture experiments indicated that $10 \pm 2 \%$ of the total number of $\beta$-tubulin-IR neurons were TH-IR. Moreover, in a proportion similar to that seen with newly generated TH-IR cells of the adult SE, $\sim 65 \%$ of the TH-IR cells were also BrdU-IR. In older cultures of dissociated neurospheres, and again analogous to the SE-derived precursors, the number of TH-IR cells did not change over time (data not shown). In these cultures, after 3 DIV, TH-IR cells acquired typical neuronal morphology, with small bipolar or multipolar cell bodies and extended long neuritic processes (Fig. 8B). After 7 DIV, a small percentage of these neurons $(<2 \%)$ exhibited a "projection neuron-like" morphology with complex neuritic arborization and long process outgrowth exceeding $0.5 \mathrm{~mm}$ (Fig. $8 \mathrm{C}$ ). Neurospheres were also grown in suspension (intact) in media containing EGF (20 ng/ml), FGF2 (20 ng/ml), and CM (75\%) (see Materials and Methods). After 7 DIV, individual clones were isolated and plated in control medium for $30 \mathrm{~min}$ to adhere to the glass coverslip. After fixation and immunocytochemistry for $\mathrm{TH}$, the clones remained in spherical shapes, which rendered the assessment of the total number of TH-IR cells per clone difficult. We counted the total number of clones that had exhibited at least one visible TH-IR soma on the surface. These data revealed that $15 \pm 2 \%$ of the plated multipotential stem cells had the potential to generate secondary clones containing TH-IR neurons (Fig. 8D).

\section{DISCUSSION}

The present study demonstrates that FGFs and glial-derived diffusible factors act synergistically to direct the forebrain neuronal precursors to a cathecholaminergic fate. This finding represents a further step in understanding how embryonic and adult precursors could be manipulated in regard to their neurotransmitter phenotype choices. Our data also support the notion that 
Figure 7. Induction of $\mathrm{TH}$ expression in precursors derived from the adult subependyma. Constitutively proliferating cells in the subependyma $(S E)$ of adult mice were first labeled in vivo by five intraperitoneal injections of BrdU (see Materials and Methods). To confirm the in vivo location of the constitutively proliferating cells, a group of mice were perfused, and the brains were cryoprotected and cryostat-sectioned. The $10 \mu \mathrm{m}$ sections were processed for BrdU immunocytochemistry. $A, B$, Drawing and photomicrograph of coronal section through the striatum of adult mouse. $B$, Photomicrograph of BrdU-IR cells within the SE surrounding the lateral ventricle. The location of this photomicrograph is outlined by the dotted lines in $A$. $C-F$, The SE cells were dissected, enzymatically dispersed, suspended in complete medium with or without FGF2 +CM, and plated in the absence of BrdU. After culture periods of 1 DIV $(C, D)$ and 3 DIV $(E, F)$, the cells were fixed and processed for dual-label indirect immunocytochemistry for $\mathrm{TH}$ and BrdU (as outlined in Materials and Methods). Photomicrographs are of newly generated cells that had incorporated $\mathrm{BrdU}$ in vivo $(C, E)$ and were TH-IR $(D, F)$ in culture treated with FGF2+CM. $a c a$, Anterior commissure, anterior; $c c$, corpus callosum; $C T X$, cortex; $L V$, lateral ventricle; $S E$, subependyma; $S T R$, striatum. Scale bar (shown in $F$ ): $B, 70 \mu \mathrm{m} ; C-F, 15 \mu \mathrm{m}$.
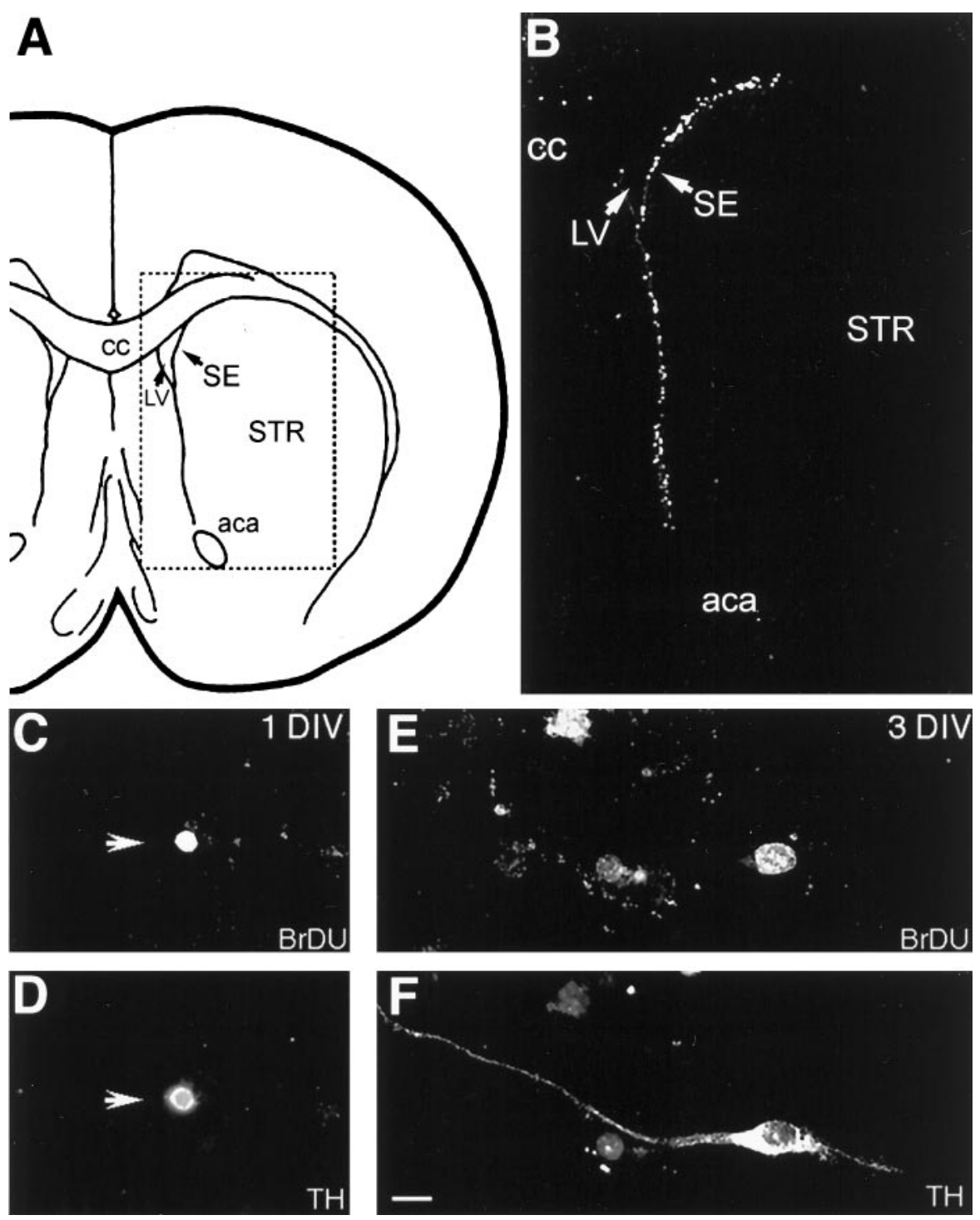

combinatorial signaling involving glia could differentially regulate neuronal lineage decisions within the mammalian CNS.

In addition to having mitogenic actions, FGF2 (and not EGF) can also stimulate $\mathrm{TH}$ gene expression in subpopulations of striatal and cortical neuronal precursors and their postmitotic progeny, cultured in a chemically defined media. These forebrainderived precursors do not express $\mathrm{TH}$ under normal conditions. The instructive TH-inducing action of FGF2 increased 2.5-fold in the presence of $0.1 \%$ serum and was dramatically potentiated by 17.5-fold in the presence of glial CM. Rather than a direct action, it is possible that FGF2+CM may act to increase the proliferation of a specific neuronal population susceptible to express $\mathrm{TH}$. However, when the striatal precursors were first labeled in vivo with a pulse of intraperitoneal BrdU injection, the number of double-labeled TH/BrdU cells in FGF2+CM-treated culture increased by fourfold (in comparison with cultures treated with BrdU at plating). These data indicate that the TH-inductive action of FGF2 + CM is independent of a direct mitotic action and that it is rather closely related to the inherent proliferative nature of the striatal precursors. In fact, delaying the application of $\mathrm{FGF} 2+\mathrm{CM}$ to the cultures resulted in the loss of striatal neuronal precursor competence to respond to the instructive actions. In aged cultures, the loss of responsiveness to the THinducing factors directly correlated with a precipitous drop in the number of proliferating cells. This phenotypic plasticity of striatal precursors is similar to that of the cerebral cortex (McConnell, 1992; Levitt et al., 1993; Ghosh and Greenberg, 1995; Götz et al., 1995) whereby newly born precursors are endowed, during an early critical period, with an intrinsic plasticity that may be related to the cell cycle/postmitotic nature of the cell. Although the exact mechanism by which $\mathrm{FGF} 2+\mathrm{CM}$ regulates $\mathrm{TH}$ expression is not clear, our observations suggest that CM promoted differentiation, at least in part, by driving the striatal precursors out of the cell cycle. We show that CM repressed FGF2-induced proliferation. One possibility is that FGF2 simultaneously activates signaling molecules required for proliferation and TH expression in striatal neuronal precursors, whereas CM modulates these two FGF2-induced intracellular signaling pathways by inhibiting the mitogenic and potentiating the TH-activated signaling pathways. It remains possible, however, that $\mathrm{FGF} 2+\mathrm{CM}$ supports the survival of a population of $\mathrm{TH}$-expressing cells that would otherwise die in the defined medium. Similar to our previous study (Daadi et al., 1998), to examine the selective (survival) versus the instructive (differentiation) actions of 

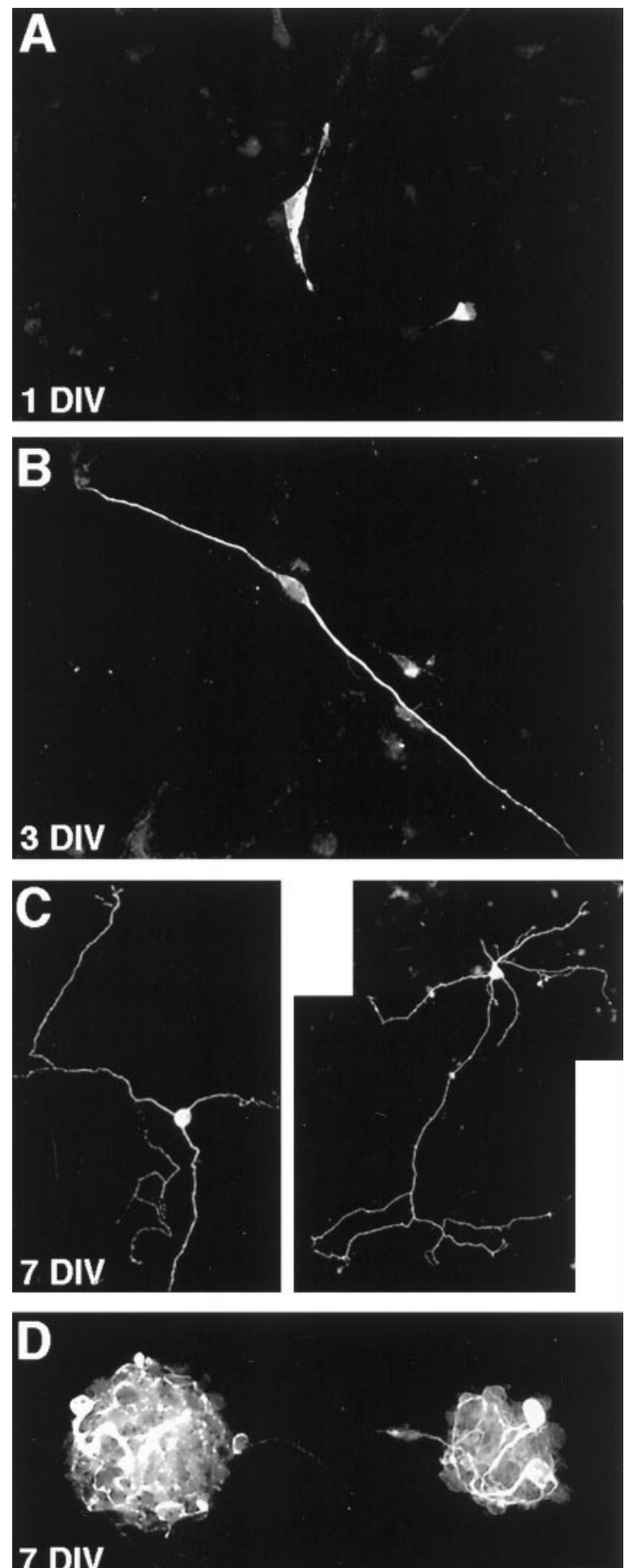

7 DIV

Figure 8. $\mathrm{CM}+\mathrm{FGF} 2$ induces $\mathrm{TH}$ expression in neuronal precursors derived from multipotential neural precursor cells. Seven-day-old neurosphere clones, grown as described in Materials and Methods, were collected and mechanically dissociated in defined medium. Dispersed cells were either plated on poly-L-ornithine-coated glass coverslips (adherent culture conditions, $A-C$ ) or replated into a $75 \mathrm{~cm}^{2}$ tissue culture flask (suspension cultures, $D$ ) in complete medium supplemented with growth factors and CM. Culture periods are indicated for each photomicrograph. Fixed cells or clones were processed for TH immunocytochemistry, as described in Materials and Methods. TH-IR cells were observed only in cultures treated with FGF2 $+\mathrm{CM}(A-D)$. $A-C$, Time course evolution of morphological characteristics acquired by the TH-IR neurons in FGF2+CM-treated cultures (see Results). D, Photomicrograph of 7-d-old TH-IR clones grown in suspension in the presence of EGF $(20 \mathrm{ng} / \mathrm{ml})$, FGF2 $(20 \mathrm{ng} / \mathrm{ml})$, and CM (75\%) (see Results). Scale bar (shown in $D)$ : $A, B, 20 \mu \mathrm{m} ; C, 50 \mu \mathrm{m} ; D, 30 \mu \mathrm{m}$
FGF2+CM, we used the life cell marker DAPI. We found that there is no difference in the number of DAPI-stained fragmented nuclei (characteristic of apoptotic cells) (Raff, 1992) between control and FGF2+CM-treated cultures (data not shown). Nevertheless, we cannot totally exclude a minimal survival action of $\mathrm{FGF} 2+\mathrm{CM}$ on certain neuronal precursors, including those that are TH-IR. Even if this occurred, the minimal survival effect would not account for the dramatic increase in TH-IR cell production (Fig. 2). The number of TH-IR neurons declined after 3 DIV, which suggests either a cell death mechanism occurring within the TH-IR subpopulation or a plasticity in neurotransmitter phenotype expression. This decline was not caused by cell death, because in our culture condition none of the TH-IR cells were undergoing apoptosis after 3 DIV, as assessed by the analysis of the structure of DAPI-stained nuclei (data not shown). This finding suggests that a downregulation of $\mathrm{TH}$ gene expression occurs within a subpopulation of the TH-IR cells. It could be that under physiological circumstances the selection of a certain phenotype requires the sustained presence of the instructive molecules and/or other factors that intervene sequentially. Indeed, specification of the dopaminergic lineage in the midbrain appears to require the continual presence (at least for a certain period of time) of FGF8 (Ye et al., 1998). Moreover, throughout adult life in the forebrain, the maintenance of $\mathrm{TH}$ expression in the olfactory bulb requires the continual presence of the synaptic activity of the olfactory afferents (Nadi et al., 1981; Baker and Farbman, 1993).

The induction of TH expression has been reported previously in noncathecholaminergic neurons. Iacovetti (1991) first demonstrated that striatal neurons could express $\mathrm{TH}$ when incubated in the presence of muscle differentiation factor (MDF). Subsequently, these investigators found that FGF1 cooperates with MDF (Du et al., 1994) or catecholamines (Du and Iacovitti, 1995) to induce TH expression. Noteworthy in these studies was that (1) newly generated cells never expressed TH, (2) striatal cells had to withdraw from the cell cycle to respond to the TH-inducing actions of MDF (Iacovetti, 1991), and (3) FGF2 was significantly less effective than FGF1 in cooperating with other molecules (Du et al., 1994). We have shown that 25 and $15 \%$ of the TH-IR striatal cells in cultures treated with FGF2 and FGF2+CM, respectively, were proliferating. Furthermore, BrdU pulselabeling studies have provided direct evidence that $\mathrm{TH}$ is induced in the mitotically active neuronal precursors (see Results). Together, these data indicate that our conditions targeted a neuronal precursor cell population. However, we cannot exclude the possibility of an overlapping between subsets of postmitotic striatal TH-IR cells in both conditions.

The vast majority $(95 \%)$ of TH-IR cells coexpressed GABA. Most of these TH-IR cells exhibited small bipolar or multipolar somas $(8-14 \mu \mathrm{m})$ with aspiny neuritic processes. Similar morphological characteristics define the striatal- and SVZ-derived GABAergic and dopaminergic interneurons that migrate tangentially to the neocortex and the olfactory bulb, respectively (Betarbet et al., 1996; De Carlos et al., 1996; Anderson et al., 1997; Luskin et al., 1997; Tamamaki et al., 1997). Interestingly, subpopulations of striatal and olfactory bulb neurons coexpress dopamine and GABA (Gall et al., 1987; Kosaka et al., 1995; Betarbet et al., 1996, 1997; Max et al., 1996). Furthermore, the neocortical neurons have the potential to express dopamine when treated in vitro with BDNF and dopamine (Zhou et al., 1994). Together with our present and previous findings (Daadi et al., 1998), these observations suggest the existence of a ganglionic 
eminence-derived bipotential neuronal precursor that can express either dopamine or GABA under specific epigenetic conditions. It is particularly noteworthy that in the adult primate, the $\mathrm{TH} /$ GABA-IR neurons described by Greenmayre and colleagues (Betarbet et al., 1997) appeared intrinsically in the striatum, and their number increased after 1-methyl-4-phenyl-1,2,3,6-tetrahydropyridine-induced dopaminergic cell loss. It would be of great interest to determine whether these cells are derived from the SE (see below for further discussion). Current experiments, whereby EGF and subsequently FGF2+CM were infused into the forebrain of adult Parkinsonian rats, favor this hypothesis (Daadi et al., 1997).

The work of Morshead and colleagues (1994, 1998) demonstrated that a relatively quiescent population of multipotential stem cells exists in the mammalian adult forebrain SE. This stem cell population generates the constitutively proliferating cells of the SE in vivo. When these mitotically active precursors (presumptive stem cell progeny) were labeled in vivo, dissected, and plated in the presence of FGF2 + CM, they expressed TH after 24 $\mathrm{hr}$ in culture. Over $3 \mathrm{~d}$, these TH-IR cells developed neuronal morphology. A subpopulation of the in vivo constitutively proliferating cells, localized in the rostral part of the SVZ, migrates postnatally and throughout the adult life to the olfactory bulb (Luskin, 1993; Lois and Alvarez-Buylla, 1994; for review, see O'Rourke, 1996). Some of these neuronal precursors migrate to the glomerular cell layer and differentiate into dopaminergic interneurons (Betarbet et al., 1996). It could be that the SE cells we induced to express TH in vitro correspond, at least in part, to the olfactory bulb dopaminergic interneurons. This hypothesis is supported by two observations. First, the low percentage in $\mathrm{TH}-$ expressing cells is similar to the in vivo conditions, whereby only $25 \%$ of the SE-derived neuronal precursors migrate to the olfactory bulb (Morshead et al., 1998) and only a minimal number of this subpopulation $(1: 30$, ratio that may be affected by cell survival; A. Alvarez-Buylla, personal communication) reaches the glomerular layer (and hence have the potential to express $\mathrm{TH}$ ) (Lois and Alvarez-Buylla, 1994). Second, there is a similarity between the morphological characteristics of the SE-derived TH-IR cells we observed and those of the in vivo migrating olfactory bulb interneuron precursors (Luskin, 1993; Menezes et al., 1995; Rousselot et al., 1995). However, numerous studies have reported that the expression of dopamine in the olfactory bulb is regulated by the olfactory sensory afferents and/or CGRP (Nadi et al., 1981; Baker et al., 1983; Denis-Donini, 1989). When tested alone or in combination with FGF2 in our bioassay, CGRP was not able to induce the TH expression in the forebrain precursor cells. Yet, previous studies suggested that neither the olfactory afferent innervation nor CGRP is sufficient to induce dopamine phenotype (Baker, 1990; Biffo et al., 1990; Finger and Böttger, 1992; Baker and Farbman, 1993). This mechanism is rather complex and may also involve indirect actions of the olfactory receptor afferents (McLean and Shipley, 1988; Finger and Böttger, 1992). The work of Baker and Farbman (1993) suggests that these olfactory afferents may regulate $\mathrm{TH}$ gene expression indirectly through the stimulation of other cell types within the glomerular cell layer and local release of growth factors. Interestingly, the olfactory bulb periglomerular and dopaminergic interneurons develop around the time of birth and postnatally (Halazs et al., 1981; Specht et al., 1981; Luskin, 1993), which suggests a possible role of glia in the differentiation process. In support of this hypothesis is the finding that the newly generated neurons of the adult forebrain SE migrate in vivo along a re- stricted pathway, called the rostral migratory stream (Altman, 1969), that is particularly enriched in astrocytes (Lois et al., 1996; Peretto et al., 1997). Within both the SE of the lateral wall of the lateral ventricle and the migratory stream, the newly generated neuronal precursors destined to migrate to the olfactory bulb are ensheathed by astrocytes (Lois et al., 1996; Doetsch et al., 1997; Peretto et al., 1997). Moreover, phenotypic specification of migrating neuronal precursors could occur through instructive actions of the migratory pathway (for review, see Hatten, 1993). Together these data demonstrate that astrocytes form an early local microenvironment for the SE neuronal precursors and suggest that glia-derived molecules may restrict the fate of these SE progeny in vivo.

In the presence of EGF, a single germinal zone-derived precursor cell will proliferate and give rise to a cluster of undifferentiated cells with the properties of neuroepithelial stem cells. We have demonstrated previously that under specific culture conditions, stem cell progenies are able to express various neurotransmitter phenotypes, including GABA, substance P, NPY, somatostatin, met-enkephalin, and glutamate (Daadi et al., 1993). The present data extend our knowledge of the developmental potential of the forebrain stem cells and demonstrate that their progeny differentiate into TH-producing cells when grown in the presence of EGF, FGF2, and CM. In dissociated cultures, $10 \%$ of the total number of neurons were induced to express TH. Using the same treatment, a similar percentage of TH-IR neurons was obtained from neurospheres derived from fetal human tissues. After numerous $(>45)$ passages, and similar to the murine neurospheres, human neurospheres were always responsive to the TH-inducing conditions (M. Daadi and A. Vescovi, unpublished results). Although $10 \%$ of the neurons express $\mathrm{TH}$, this translates to a relatively small number of neurons per coverslip. This observation is not surprising because most $(\sim 80 \%)$ of the EGFgenerated progeny of stem cells are astrocytes (see Results). However, it is important to stress that in contrast to the embryonic striatal cells, we have never seen a single TH-IR neuron in control cultures derived from both EGF-generated precursors and those derived directly from the adult SE. This observation renders the instructive actions on the later two sources of cells (although only a small percentage are TH-IR cells) to be rather significant. To increase the number of TH-expressing neurons, it may be useful to first promote the neuronal lineage of precursor cells (Ahmed et al., 1995; Johe et al., 1996; Mayer-Proschel et al., 1997; Williams et al., 1997; Arsenijevic and Weiss, 1998). Nevertheless, it remains unresolved why, in general, only a small proportion of neuronal precursors are susceptible to the induction of TH. This could be attributable to the presence of other instructive molecules in $\mathrm{CM}$ that are more potent in promoting other lineage species or to the low concentration of the TH-inducing factors present in the CM. Alternatively, it could be that the majority of neuronal precursors are endowed with a restricted range of fate. The weak potency of $\mathrm{CM}$ derived from embryonic astroglia (relative to B49 CM) favors the second hypothesis. Moreover, after partial purification of glial CM, and when combined with FGF2, the isolated active fraction was more potent and consistent (than $\mathrm{CM}$ ) in inducing $\mathrm{TH}$ expression in stem cell progeny (M. Daadi, unpublished results).

When FGF2 was combined with BDNF, CNTF, PDGF, TGF $\alpha$, TGF $\beta 2-3$, activin-A, BMP-2, GDNF, Shh, or CGRP, we were not able to see any induction of $\mathrm{TH}$ expression in the in vitro-generated forebrain multipotential stem cell progeny. These observations suggest that a novel glial differentiation factor(s) is 
responsible for this action. However, given the small number of TH-IR neurons derived from stem cells, it is difficult to make a firm assessment regarding the involvement of the other known molecules in $\mathrm{TH}$ gene regulation. It could be that these molecules, in cooperation with FGF2, had a minimal inductive effect that was undetectable by our immunocytochemical techniques. Because Shh is required for the midbrain dopaminergic neuron specification (Hynes et al., 1995a,b, 1997; Wang et al., 1995), the fact that it did not induce $\mathrm{TH}$ expression in forebrain-derived neuronal precursors is intriguing. There are many possible explanations. The difference in the embryonic age, the spatial location, and in vitro culture conditions may explain the different responsiveness of neuronal precursors to the same set of molecules. Second, it could be that during development Shh acts earlier than the glial-derived differentiation factors (described in this report) in concert with FGFs. Third, the midbrain and forebrain dopaminergic neurons may require different factors and likely separate mechanisms for their specification. In favor of this last hypothesis is the finding that in contrast to the olfactory bulb dopaminergic cells, the midbrain dopaminergic neurons failed to develop in the orphan nuclear receptor Nurr1 null mice (Zetterström et al., 1997; T. Perlmann, personal communication).

\section{Significance of the finding}

It has been well established that astroglial cells function as a support for migrating neuronal precursors in the developing brain and provide physiological assistance to neuronal functions in the mature brain. The present study suggests that glial diffusible factors may also instruct neuronal precursors to commit to a particular neuronal lineage. This represents a further step in understanding the inherent ability of the mammalian brain to generate diverse cell types and could help in developing successful therapeutic strategies for the treatment of Parkinson's disease.

\section{REFERENCES}

Ahmed S, Reynolds BA, Weiss S (1995) BDNF enhances the differentiation but not survival of CNS stem cell-derived neuronal precursors. J Neurosci 15:5765-5778.

Altman J (1969) Autoradiographic and histological studies of postnatal neurogenesis. IV. Cell proliferation and migration in the anterior forebrain with special reference to persisting neurogenesis in the olfactory bulb. J Comp Neurol 137:433-458.

Anderson DJ (1989) The neural crest cell lineage problem: neuropoiesis? Neuron 3:1-12.

Anderson DJ (1992) The sympathoadrenal progenitor of the neural crest: basic biology and therapeutic potential. In: Gene transfer and therapy in the nervous system (Gage F, Christen Y, eds), pp 40-58. Berlin: Springer.

Anderson SA, Eisenstat DD, Shi L, Rubenstein JLR (1997) Interneuron migration from basal forebrain to neocortex: Dependence on Dlx genes. Science 278:474-476.

Arsenijevic Y, Weiss S (1998) Insulin-like growth factor-I is a differentiation factor for postmitotic CNS stem cell-derived neuronal precursors: distinct actions from those of brain-derived neurotrophic factor. J Neurosci 18:2118-2128.

Baetge EE (1993) Neural stem cells for CNS transplantation. Ann NY Acad Sci 695:285-291.

Baker H (1990) Calcitonin gene-related peptide in the developing mouse olfactory system. Dev Brain Res 54:295-298.

Baker H, Farbman AI (1993) Olfactory afferent regulation of the dopamine phenotype in the fetal rat olfactory system. Neuroscience 52:115-134.

Baker H, Kawano T, Margolis FL, Joh TH (1983) Transneuronal regulation of tyrosine hydroxylase expression in olfactory bulb of mouse and rat. J Neurosci 3:69-78.

Betarbet R, Zigova T, Bakay RAE, Luskin MB (1996) Dopaminergic and GABAergic interneurons of the olfactory bulb are derived from the neonatal subventricular zone. Int J Dev Neurosci 14:921-930.
Betarbet R, Turner R, Chockkan V, DeLong MR, Allers KA, Walters J, Levey AI, Greenamyre JT (1997) Dopaminergic neurons intrinsic to the primate striatum. J Neurosci 17:6761-6768.

Biffo S, DeLucia R, Mulatero B, Margolis F, Fasolo A (1990) Carnosine-, calcitonin gene-related peptide- and tyrosine hydroxylaseimmunoreactivity in the mouse olfactory bulb following peripheral denervation. Brain Res 528:353-357.

Boulder Committee (1970) Embryonic vertebrate central nervous system: revised terminology. Anat Rec 166:257-261.

Bouvier MM, Mytilineou C (1995) Basic fibroblast growth factor increases division and delays differentiation of dopamine precursors in vitro. J Neurosci 15:7141-7149.

Brüstle O, McKay RDG (1996) Neuronal progenitors as a tool for cell replacement in the nervous system. Curr Opin Neurobiol 6:688-695.

Cattaneo E, McKay RDG (1990) Proliferation and differentiation of neuronal stem cells regulated by nerve growth factor. Nature 347:762-765.

Daadi M, Hassam R, Reynolds BA, Weiss S (1993) Co-culture of EGFgenerated progenitor cells with post-natal astrocytes. Soc Neurosci Abstr 19:360.8.

Daadi M, Dicay M, Reynolds BA, Poulin P (1997) In vivo manipulation of the CNS stem cell progeny to generate tyrosine hydroxylase expressing neurons in Parkinsonian animal model. Soc Neurosci Abstr 23:131.7.

Daadi M, Arcellana-Panlilio MY, Weiss S (1998) Activin co-operates with FGF2 to regulate tyrosine hydroxylase expression in the basal forebrain ventricular zone progenitors. Neuroscience 86:867-880.

De Carlos JA, Lopez-Mascaraque L, Valverde F (1996) Dynamics of cell migration from the lateral ganglionic eminence in the rat. J Neurosci 16:6164-6156.

Denis-Donini S (1989) Expression of dopaminergic phenotypes in the mouse olfactory bulb induced by the calcitonin gene-related peptide. Nature 339:701-703.

Denis-Donini S, Glowinski SJ, Prochiantz A (1984) Glial heterogeneity may define the three-dimensional shape of mouse mesencephalic dopaminergic neurones. Nature 307:641-643.

Doetsch F, Garcia-Verdugo JM, Alvarez-Buylla A (1997) Cellular composition and three-dimensional organization of the subventricular germinal zone in the adult mammalian brain. J Neurosci 17:5046-5061.

Du X, Iacovitti L (1995) Synergy between growth factors and transmitters required for catecholamine differentiation in brain neurons. J Neurosci 15:5420-5427.

Du X, Stull ND, Iacovitti L (1994) Novel expression of the tyrosine hydroxylase gene requires both acidic fibroblast growth factor and an activator. J Neurosci 14:7688-7694.

During MJ, Naegele JR, O'Malley KL, Geller AI (1994) Long-term behavioral recovery in parkinsonian rats by an HSV vector expressing tyrosine hydroxylase. Science 266:1399-1403.

Edlund T, Jessell TM (1999) Progression from extrinsic to intrinsic signaling in cell fate specification: a view from the nervous system. Cell 96:211-224.

Engele J, Bohn MC (1991) The neurotrophic effects of fibroblast growth factors on dopaminergic neurons in vitro are mediated by mesencephalic glia. J Neurosci 11:3070-3078.

Engele J, Schubert D, Bohn MC (1991) Conditioned media derived from glial cell lines promote survival and differentiation of dopaminergic neurons in vitro: role of mesencephalic glia. J Neurosci Res 30:359-371.

Ferrari G, Minozzi M-C, Toffano G, Leon A, Skaper SD (1989) Basic fibroblast growth factor promotes the survival and development of mesencephalic neurons in culture. Dev Biol 133:140-147.

Finger TE, Böttger B (1992) Expression of the dopaminergic phenotype in the olfactory bulb: neither calcitonin gene-related peptide nor olfactory input is necessary. Neurosci Lett 143:15-18.

Fisher LJ (1997) Neural precursor cells: application for the study and repair of the central nervous system. Neurobiol Dis 4:1-22.

Fisher LJ, Jinnah HA, Kale LC, Higgins GA, Gage FH (1991) Survival and function of intrastriatally grafted primary fibroblasts genetically modified to produce L-dopa. Neuron 6:371-380.

Gage FH (1998) Cell therapy. Nature [Suppl] 392:18-24.

Gage FH, Ray J, Fisher LJ (1995) Isolation characterization and use of stem cells from the CNS. Annu Rev Neurosci 18:159-192.

Gall CM, Hendry SHC, Seroogy KB, Jones EG, Haycock JW (1987) Evidence for coexistence of GABA and dopamine in neurons of the rat olfactory bulb. J Comp Neurol 266:307-318.

Gaul G, Lubbert H (1992) Cortical astrocytes activated by basic fibro- 
blast growth factor secrete molecules that stimulate differentiation of mesencephalic dopaminergic neurons. Proc R Soc Lond B Biol Sci 249:57-63.

Gensburger C, Labourdette G, Sensenbrenner M (1987) Brain basic fibroblast growth factor stimulates the proliferation of rat neuronal precursor cells in vitro. FEBS Lett 217:1-5.

Ghosh A, Greenberg ME (1995) Distinct roles for bFGF and NT-3 in the regulation of cortical neurogenesis. Neuron 15:89-103.

Götz M, Williams BP, Bolz J, Price J (1995) The specification of neuronal fate: a common precursor for neurotransmitter subtypes in the rat cerebral cortex in vitro. Eur J Neurosci 7:889-898.

Gratzner HG (1982) Monoclonal antibody to 5-bromo- and 5-iododeoxyuridine: a new reagent for detection of DNA replication. Science 218:474-475.

Gritti A, Parati EA, Cova L, Frolichsthal P, Galli R, Wanke E, Faravelli L, Morassutti DJ, Roisen F, Nickel DD, Vescovi AL (1996) Multipotential stem cells from the adult mouse brain proliferate and self-renew in response to basic fibroblast growth factor. J Neurosci 16:1091-1100.

Halasz N, Johansson O, Hokfelt T, Ljungdahl A, Goldstein M (1981) Immunohistochemical identification of two types of dopamine neuron in rat olfactory bulb as seen by serial sectioning. J Neurocytol 10:251-259.

Hatten ME (1993) The role of migration in central nervous system neuronal development. Curr Opin Neurobiol 3:38-44.

Herman JP, Abrous ND (1994) Dopaminergic neural grafts after fifteen years: results and perspectives. Prog Neurobiol 44:1-35.

Hourellou P, Brundin P, Kalen P, Mallet J, Björklund A (1990) In vivo release of DOPA and dopamine from genetically engineered cells grafted to the denervated rat striatum. Neuron 5:393-402.

Horellou P, Vigne E, Castel MN, Barneoud P, Colin P, Perricaudet M, Delaere P, Mallet J (1994) Direct intracerebral gene transfer of an adenoviral vector expressing tyrosine hydroxylase in rat model of Parkinson's disease. NeuroReport 6:49-53.

Hynes MA, Poulsen, K, Tessier-Lavigne M, Rosenthal A (1995a) Control of neuronal diversity by floor plate: contact-mediated induction of midbrain dopaminergic neurons. Cell 80:95-101.

Hynes MA, Porter JA, Chiang C, Chang D, Tessier-Lavigne M, Beachy PA, Rosenthal A (1995b) Induction of midbrain dopaminergic neurons by sonic hedgehog. Neuron 15:35-44.

Hynes MA, Stone DM, Dowd M, Pitts-Meek S, Goddard A, Gurney A, Rosenthal A (1997) Control of cell pattern in the neural tube by zinc finger transcription factor and oncogene Gli-1. Neuron 19:15-26.

Iacovitti L (1991) Effects of a novel differentiation factor on the development of catecholamine traits in noncatecholamine neurons from various regions of the rat brain: studies in tissue culture. J Neurosci 11:2403-2409.

Ichikawa S, Sasaoka T, Nagatsu T (1991) Primary structure of mouse tyrosine hydroxylase deduced from its cDNA. Biochem Biophys Res Commun 176:1610-1616.

Jiao S, Vladimir G, Wolff JA (1993) Long-term correction of rat model of Parkinson's disease by gene therapy. Nature 362:450-453.

Johe KK, Hazel TG, Muller T, Dugich-Djordjevic MM, McKay RDG (1996) Single factors direct the differentiation of stem cells from fetal and adult central nervous system. Genes Dev 10:3129-3140.

Kaplitt MG, Leone P, Samulski RJ, Xiao X, Pfaff DW, O'Malley KL, During MJ (1994) Long-term gene expression and phenotypic correction using adeno-associated virus vectors in the mammalian brain. Nat Genet 8:148-154.

Kilpatrick TJ, Bartlett PF (1993) Cloning and growth of multipotential neuronal precursors: requirements for proliferation and differentiation. Neuron 10:255-265.

Knusel B, Michel P, Schwaber J, Hefti F (1990) Selective and nonselective stimulation of central cholinergic and dopaminergic development in vitro by nerve growth factor basic fibroblast growth factor epidermal growth factor insulin and insulin-like growth factors I and II. J Neurosci 10:558-570.

Kosaka K, Aika Y, Toida K, Heizmann CW, Hunziker W, Jacobowitz DM, Nagatsu I, Streit P, Visser TJ, Kosaka T (1995) Chemically defined neuron groups and their subpopulations in the glomerular layer of the rat olfactory bulb. Neurosci Res 23:73-88.

Lee MK, Tuttle JB, Rebhun LI, Cleveland DW, Frankfurter A (1990) The expression and post-translational modification of a neuron-specific $\beta$-tubulin isotype during chick embryogenesis. Cell Motil Cytoskeleton $17: 118-132$.

Levitt P, Ferri RT, Barbe MF (1993) Progressive acquisition of cortical phenotypes as a mechanism for specifying the developing cerebral cortex. Perspect Dev Neurobiol 1:65-74.

Lin LF, Doherty DH, Lile JD, Bektesh S, Collins F (1993) GDNF: a glial cell line-derived neurotrophic factor for midbrain dopaminergic neurons. Science 260:1130-1132.

Lois C, Alvarez-Buylla A (1994) Long-distance neuronal migration in the adult mammalian brain. Science 264:1145-1148.

Lois C, Garcia-Verdugo JM, Alvarez-Buylla A (1996) Chain migration of neuronal precursors. Science 271:978-981.

Luskin MB (1993) Restricted proliferation and migration of postnatally generated neurons derived from the forebrain subventricular zone. Neuron 11:173-189.

Luskin MB, Zigova T, Soteres BT, Stewart RR (1997) Neuronal progenitor cells derived from the anterior subventricular zone of the neonatal rat forebrain continue to proliferate in vitro and express a neuronal phenotype. Mol Cell Neurosci 8:351-366.

Mallet J (1996) Catecholamines: from gene regulation to neuropsychiatric disorders. Trends Neurosci 19:191-196.

Max SR, Bossio A, Iacovitti L (1996) Co-expression of tyrosine hydroxylase and glutamic acid decarboxylase in dopamine differentiation factor-treated striatal neurons in culture. Dev Brain Res 91:140-142.

Mayer E, Dunnett SB, Fawcett JW (1993) Mitogenic effect of basic fibroblast growth factor on embryonic ventral mesencephalic dopaminergic neuron precursors. Brain Res Dev Brain Res 72:253-258.

Mayer-Proschel M, Kalyani AJ, Mujtaba T, Rao MS (1997) Isolation of lineage-restricted neuronal precursors from multipotent neuroepithelial stem cells. Neuron 19:773-785.

McConnell SK (1992) The control of neuronal identity in the developing cerebral cortex. Curr Opin Neurobiol 2:23-27.

McLean JH, Shipley MT (1988) Postmitotic postmigrational expression of tyrosine hydroxylase in olfactory bulb dopaminergic neurons. J Neurosci 8:3658-3669.

Menezes JRL, Smith CM, Nelson K, Luskin MB (1995) The division of neuronal progenitor cells during migration in the neonatal mammalian forebrain. Mol Cell Neurosci 6:496-508.

Mizuno K, Carnahan J, Nawa H (1994) Brain-derived neurotrophic factor promotes differentiation of striatal GABAergic neurons. Dev Biol 165:243-256.

Morshead CM, van der Kooy D (1992) Postmitotic death is the fate of constitutively proliferating cells in the subependymal layer of the adult brain. J Neurosci 12:249-256.

Morshead CM, Reynolds BA, Craig CG, McBurney MW, Staines WA, Morassutti D, Weiss S, van der Kooy D (1994) Neural stem cells in the adult mammalian forebrain: a relatively quiescent subpopulation of subependymal cells. Neuron 13:1071-1082.

Morshead CM, Craig CG, van der Kooy D (1998) In vivo clonal analyses reveal the properties of endogenous neural stem cell proliferation in the adult mammalian forebrain. Development 125:2251-2261.

Mugnaini E, Oertel WH (1985) An atlas of the distribution of GABAergic neurons and terminals in the rat CNS as revealed by GAD immunocytochemistry. In: GABA and neuropeptides in the CNS, Handbook of chemical neuroanatomy, Vol 4, Part I (Björklund A, Hokfelt T, eds), pp 436-608. Amsterdam: Elsevier.

Murphy M, Drago J, Bartlett PF (1990) Fibroblast growth factor stimulates the proliferation and differentiation of neuronal precursor cells in vitro. J Neurosci Res 25:463-475.

Nadi NS, Head R, Grillo M, Hempstead J, Granno-Reisfeld N, Margolis FL (1981) Chemical deafferentation of the olfactory bulb: plasticity of the levels of tyrosine hydroxylase dopamine and neurepinephrine. Brain Res 213:365-377.

Olanow CW, Kordower JH, Freeman TB (1996) Fetal nigral transplantation for the treatment of Parkinson's disease. Trends Neurosci 19:102-108.

O’Malley EK, Sieber BA, Black IB, Dreyfus CF (1992) Mesencephalic type I astrocytes mediate the survival of substantia nigra dopaminergic neurons in culture. Brain Res 582:65-70.

O'Rourke NA (1996) Neuronal chain gangs: homotypic contacts support migration into the olfactory bulb. Neuron 16:1061-1064.

Peretto P, Merighi A, Fasolo A, Bonfanti L (1997) Glial tubes in the rostral migratory stream of the adult rat. Brain Res Bull 42:9-21.

Qian X, Davis AA, Goderie SK, Temple S (1997) FGF2 concentration regulates the generation of neurons and glia from multipotent cortical stem cells. Neuron 18:81-93.

Raff MC (1992) Social controls of cell survival and cell death. Nature 356:397-400. 
Ray J, Gage FH (1994) Spinal cord neuroblasts proliferate in response to basic fibroblast growth factor. J Neurosci 14:3548-3564.

Ray J, Peterson DA, Schinstine M, Gage FH (1993) Proliferation differentiation and long-term culture of primary hippocampal neurons. Proc Natl Acad Sci USA 90:3602-3606.

Raymon HK, Thode S, Gage FH (1997) Application of ex vivo gene therapy in the treatment of Parkinson's disease. Exp Neurol 144:82-91.

Reynolds BA, Weiss S (1992) Generation of neurons and astrocytes from isolated cells of the adult mammalian central nervous system. Science 255:1707-1710.

Richards LJ, Kilpatrick TJ, Bartlett PF (1992) De novo generation of neuronal cells from the adult mouse brain. Proc Natl Acad Sci USA 89:8591-8595.

Rousselot P, Lois C, Alvarez-Buylla A (1995) Embryonic (PSA) $\mathrm{N}-\mathrm{CAM}$ reveals chains of migrating neuroblasts between the lateral ventricle and the olfactory bulb of adult mice. J Comp Neurol 351:51-61.

Schubert D, Heinemann S, Carlisle W, Tariskas H, Kimes B, Patrick J, Steinbach JH, Culp W, Brandt BL (1974) Clonal cell lines from the rat central nervous system. Nature 249:224-227.

Specht LA, Pickel VM, Joh TH, Reiss DJ (1981) Light microscopic immunocytochemical localization of tyrosine hydroxylase in prenatal rat brain. II. Late ontogeny. J Comp Neurol 199:255-276.

Studer L, Tabar V, McKay RDG (1998) Transplantation of expanded mesencephalic precursors leads to recovery in parkinsonian rats. Nat Neurosci 1:290-295.

Takeshima T, Johnston JM, Commissiong JW (1994) Mesencephalic type 1 astrocytes rescue dopaminergic neurons from death induced by serum deprivation. J Neurosci 14:4769-4779.

Tamamaki N, Fujimori KE, Takauji R (1997) Origin and route of tan- gentially migrating neurons in the developing neocortical intermediate zone. J Neurosci 17:8313-8323.

Wang MZ, Jin P, Bumcrot DA, Marigo V, McMahon AP, Wang EA, Woolf T, Pang K (1995) Induction of dopaminergic neuron phenotype in the midbrain by sonic hedgehog protein. Nat Med 1:1184-1188.

Weiss S, van der Kooy D (1998) CNS stem cells: where's the biology (a.k.a. beef)? J Neurobiol 36:307-314.

Weiss S, Reynolds BA, Vescovi AL, Morshead CM, Craig CG, van der Kooy D (1996) Is there a neural stem cell in the mammalian forebrain? Trends Neurosci 19:387-393.

Whittemore SR, Snyder EY (1996) Physiological relevance and functional potential of central nervous system-derived cell lines. Mol Neurobiol 12:13-38.

Williams BP, Park JK, Alberta JA, Muhlebach SG, Hwang GY, Roberts TM, Stiles CD (1997) A PDGF-regulated immediate early gene response initiates neuronal differentiation in ventricular zone progenitor cells. Neuron 18:553-562.

Wolff JA, Fisher LJ, Xu L, Hyder AJ, Langlais PJ, Iuvone PM, O’Malley KL, Rosenbert MD, Shimohama S, Freidmann T, Gage FH (1989) Grafting fibroblasts genetically modified to produce L-DOPA in rat model of Parkinson's disease. Proc Natl Acad Sci USA 86:9011-9014.

Ye W, Shimamura K, Rubenstein JLR, Hynes MA, Rosenthal A (1998) FGF and SHH signals control dopaminergic and serotonergic cell fate in the anterior neural plate. Cell 93:755-766.

Zetterström RH, Solomin L, Jansson L, Hoffer BJ, Olson L, Perlmann T (1997) Dopamine neuron agenesis in Nurr1-deficient mice. Nature 276:248-250

Zhou J, Bradford HF, Stern GM (1994) The stimulatory effect of brainderived neurotrophic factor on dopaminergic phenotype expression of embryonic rat cortical neurons in vitro. Dev Brain Res 81:318-324. 